\title{
LA RED TELEFÓNICA DE GUIPÚZCOA DURANTE LA GUERRA CIVIL ESPAÑOLA
}

\section{THE TELEPHONE NETWORK OF GIPUZKOA DURING THE SPANISH CIVIL WAR}

\author{
Pablo Soler Ferrán*, José Ramón Iglesia Medina \\ Foro Histórico de las Telecomunicaciones, Madrid, España
}

RESUMEN: Son conocidos los análisis sobre la economía, finanzas y algunos sectores industriales en la Guerra Civil española. En cambio, ha sido relativamente poco estudiado el papel jugado en dicha contienda por el sector de las telecomunicaciones. Analizamos aquí un caso concreto: la gestión durante el conflicto de la Red Telefónica Provincial de Guipúzcoa (RTG), que estuvo desde finales de septiembre de 1936 bajo control franquista excepto la central telefónica de Eibar que siguió en zona republicana hasta marzo de 1937.

En base a documentos de diferentes archivos, se analizan diversos aspectos que ejemplifican la importancia estratégica de las redes telefónicas en la Guerra Civil, en este caso la guipuzcoana.

En conclusión, se valida parcialmente, con el caso concreto de la RTG, la importancia del estudio de las redes telefónicas para entender globalmente el desarrollo del conflicto, haciéndose necesario extender el análisis a la Compañía Telefónica Nacional de España.

PALABRAS CLAVE: Historia de la Telefonía; Guerra Civil Española; Red Telefónica de Guipúzcoa.

\begin{abstract}
While there are a number of studies on how the Spanish Civil War affected the national economy and industry, the impact on Telecomunications has not been researched in depth. In the present work we analyse the Telephone Network of Gipuzkoa, which fell to Franco's army in September 1936, with the sole exception of Eibar's telephone exchange, which remained with the republicans until March 1937.

Thanks to preserved documents in a number of archives, we discuss several issues that highlight the strategical significance of the Telephonic Networks in the Spanish Civil War.

This work shows, as a partial conclusion applicable to the Telephone Network of Gipuzkoa, the importance of assessing the Telephonic Networks in order to have a full understanding of the Civil War in Spain. Further studies on the Compañia Telefónica Nacional de España would therefore be of much needed.
\end{abstract}

KEYWORDS: History of Telephony; Spanish Civil War; Telephone Network of Gipuzkoa.

* Correspondencia a: Pablo Soler Ferrán. Foro Histórico de las Telecomunicaciones, Asociación Española de Ingenieros de Telecomunicación, c/General Arrando, 38 (28010, Madrid) - ferranpablo@gmail.com - https://orcid.org/0000-00021987-4766

Cómo citar: Soler Ferrán, Pablo; Iglesia Medina, José Ramón (2020). «La red telefónica de Guipúzcoa durante la Guerra Civil española»; Historia Contemporánea, 62, 79-117. (https://doi.org/10.1387/hc.20160).

Recibido: 7 septiembre, 2018; aceptado: 10 abril, 2019.

ISSN 1130-2402 - elSSN 2340-0277 / ㄷ 2020 UPV/EHU

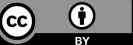

Esta obra está bajo una licencia

Creative Commons Atribución 4.0 Internacional 


\section{Introducción}

Durante la Segunda Revolución Industrial se consolida e institucionaliza paulatinamente el sector de los servicios y entre ellos el de las telecomunicaciones. Con un inicio complejo y con diferentes modelos de desarrollo según los países, se conforman durante las primeras décadas del siglo XX en España las primeras empresas operadoras concesionarias del servicio telefónico, concentrándose fuertemente sobre un mínimo número de ellas a partir de 1924, tras la concesión del monopolio a la Compañía Telefónica Nacional de España (CTNE) durante la Dictadura de Primo de Rivera.

Posteriormente, en julio de 1936 se produjo el Golpe de Estado que dio inicio a la Guerra Civil española (GCE), conflicto que vino a incidir en todos los ámbitos de la vida del país y, lógicamente, también en las telecomunicaciones y, en concreto, en las redes telefónicas civiles. Pero, como veremos, la influencia fue mutua, siendo el control sobre la gestión del servicio telefónico un factor a tener en cuenta para un análisis global de la contienda. En definitiva: ¿Qué fue de estas empresas durante la guerra civil y la inmediata posguerra (coincidente con la Segunda Guerra Mundial)? ¿Cómo fue el uso militar de las redes telefónicas civiles? ¿En qué medida fue trascendente el comercio exterior relativo al sector de las telecomunicaciones? Estas son las cuestiones que nos planteamos.

La GCE ha generado una ingente bibliografía sobre su historia política y militar; también, aunque en menor medida, sobre la económica y la de algunos sectores industriales en ambas zonas en conflicto. En cambio, se ha profundizado poco en la historia de un sector estratégico como es el de las telecomunicaciones, aunque sí ha sido indirectamente indicado el papel crucial del teléfono en la sublevación del 18 de julio. Así, el historiador Alía Miranda analizó los acontecimientos del golpe en las principales ciudades españolas, y prácticamente en todos los casos se destaca la importancia del control, por ambos bandos, de los respectivos edificios de teléfonos y telégrafos, independientemente de que triunfara la sublevación o no. También Hugh Thomas afirmaba que el Golpe de Estado de julio de 1936 «había sido la primera rebelión de la era del teléfono». ${ }^{1}$

A su vez, Francisco Comín ha señalado la importancia de extender los análisis puramente políticos y militares de la GCE a la economía y

1 Alía Miranda, 2011; Thomas, 1976, p. 363. 
los sectores industriales durante la contienda en ambos bandos. Por eso mismo llama la atención la ausencia del sector de las telecomunicaciones en una obra colectiva tan exhaustiva coordinada por él, bajo la dirección del economista Enrique Fuentes Quintana, Economía y economistas españoles en la Guerra Civil. En esta monografía, además de los aspectos puramente económicos y financieros, se analiza la importancia de los ferrocarriles, de empresas para el suministro de gasolina como CAMPSA, y de otros sectores industriales (analizándose la gestión en los dos bandos, ya que, por ejemplo, hubo dos empresas CAMPSA, la republicana y la nacional). Algo similar ocurre con la financiación del bando nacional, la ayuda alemana y el comercio exterior. Hay multitud de trabajos académicos sobre estos aspectos y la ausencia del sector de las telecomunicaciones es casi total. ${ }^{2}$ Lo mismo ocurre en trabajos actuales sobre la historiografía de la GCE, que incluyen análisis específicos de la económica pero sin referencias sobre telecomunicaciones. ${ }^{3}$

A pesar de la citada escasez de estudios específicos, y apoyando las cualificadas afirmaciones mencionadas, planteamos la hipótesis de que, efectivamente, el estudio de las telecomunicaciones y su sector empresarial es fundamental para entender de forma global el desarrollo de la GCE. Por ejemplo, es conocido que uno de los factores favorables para el triunfo final de los sublevados fue la unidad de mando y el control de diversos aspectos de la vida civil, como la industria, frente a los problemas de la República para ejercer de forma inequívoca el mando militar y el control industrial y económico. Pues bien, también en la gestión de las redes telefónicas civiles se dio esta situación contrapuesta en las dos zonas, como veremos.

Es evidente la trascendental importancia de las transmisiones militares para la operatividad de un ejército en un conflicto bélico, no en vano, la alemana Legión Cóndor dispuso de un cuerpo de transmisiones

2 Por ejemplo, las monografías de Fuentes y Comín, 2008, Sánchez Asiaín, 2012 y Martínez Ruiz, 2006, siendo muy exhaustivas sobre temas económicos, financieros, sobre comercio exterior, sobre diversos sectores industriales, ferrocarriles, energía, etc, de la GCE no tratan nada sobre el sector de las telecomunicaciones. En cambio, sí aparece algo de este sector en la GCE en Borreguero, 2017.

${ }^{3}$ Viñas y Blanco, 2017, es una monografía que actualiza y completa un número especial de 2014 de la revista Studia Historica Historia Contemporánea sobre la historiografía de la GCE. Los trabajos específicos sobre la historiografía económica son los de Barciela y López, 2014 y 2017. 
en España durante de la GCE. ${ }^{4}$ Pero, a su vez, en una contienda bélica el uso militar de las comunicaciones civiles es igualmente necesario (por ejemplo para tendidos de líneas y uso de centrales telefónicas manuales, donde se aprovechaban las civiles). Por otra parte, el uso de las propias redes civiles es también estratégico para ejercer el control político en la retaguardia.

En definitiva, se hace necesario investigar en torno a la historia de las operadoras del servicio telefónico en el periodo bélico, y fundamentalmente la de la CTNE, actor casi total en aquellos momentos en toda la geografía del conflicto. En realidad hubo dos CTNE, una en el bando republicano que continuaba siendo gestionada por la americana International Telephone \& Telegraph (ITT), y otra en el bando nacional bajo control directo del Gobierno de Burgos. Es cierto que, en el marco de la historia de las telecomunicaciones en España, se han realizado algunas aproximaciones sobre el devenir en la GCE de la CTNE y su principal suministradora, Standard Eléctrica, como las del historiador Angel Calvo, pero han sido menores, sin analizar en detalle la situación específica de la guerra. ${ }^{5}$ Otro problema fundamental es el de los archivos de Telefónica, que no están abiertos para su consulta.

Volviendo a la situación del servicio telefónico en España, en 1936 había tres excepciones en el monopolio que ejercía la CTNE: la red telefónica insular de Tenerife, la provincial de Guipúzcoa y la urbana de San Sebastián. La primera fue absorbida por la CTNE en $1938^{6}$, y las otras dos se mantuvieron a cargo de la Diputación Provincial de Guipúzcoa y el Ayuntamiento de San Sebastián, por las específicas condiciones de sus concesiones en la primera década del siglo XX. Y en estos dos casos, sí hay disponibilidad pública de archivos que permitan analizar la gestión de ambas redes.

Proponemos aquí el análisis del caso concreto de la gestión de la Red Telefónica Provincial de Guipúzcoa (RTG) durante la contienda. Comprobaremos cómo la gestión y circunstancias de la RTG durante el pe-

${ }^{4}$ Iglesia y Soler, 2017.

5 Calvo, 2010 y 2014. En Calvo, 2010, se citan actas del Consejo de Administración y del Comité Ejecutivo de la CTNE durante la GCE, pero no hemos conseguido acceder a dichos documentos.

${ }^{6}$ Proyecto de cesión de la Red Telefónica Insular a la CTNE, Libro de Actas del Cabildo de Tenerife 1938, sesión 12-07-1938. Accesible en http://www.canaltenerifetv.com/ media/libro-de-actas-020-1937-1938, pp. 234-247. 
riodo estudiado tuvo influencia tanto en el ámbito civil como en el militar durante el conflicto.

La RTG pertenecía entonces a una administración pública, en concreto la Diputación Provincial, ya que no se integró en la CTNE hasta 1949. Estuvo desde finales de septiembre de 1936 bajo control franquista, excepto la zona de Eibar que se mantuvo en zona republicana hasta marzo de 1937.

Otro caso es el de la Red Telefónica Urbana Municipal de San Sebastián, que no fue integrada en la CTNE hasta 1970. Ambas redes tuvieron un suministrador común para el proceso de automatización, la empresa sueca L. M. Ericsson. Nuestro trabajo se vería completado con un análisis similar para esta red, y lo que requiere una investigación específica.

Nuestra propuesta tiene un doble objetivo: por un lado, puramente histórico, desde la óptica de la Historia de las Telecomunicaciones, analizar la gestión de la RTG durante la GCE y comprobar en qué medida pudo influir en la marcha de la guerra y cómo el propio conflicto influyó en la gestión de la red; por otro, historiográfico, para, a partir de un caso particular y un entorno concreto, poner en valor la necesidad de extender el análisis a la CTNE y por tanto a la principal red de telecomunicaciones civiles.

Nuestro trabajo se basa principalmente en fuentes primarias de archivos, mayoritariamente los fondos de la Diputación Foral de Guipúzcoa y los de Ericsson España. La mayoría de los documentos citados se hayan disponibles para su consulta en la web y existe además una catalogación completa de los fondos archivísticos relacionados. Esta disponibilidad facilitará la contrastación y/o ampliación de este estudio por terceros. ${ }^{7}$

\section{Antecedentes. La Red Telefónica Provincial}

La situación de las redes telefónicas en España inmediatamente antes de la Guerra Civil es bien conocida. ${ }^{8}$ Había un monopolio estatal que ejercía la CTNE, filial de la norteamericana ITT, con la excepción ya señalada de tres redes de ámbito local o provincial. Antes de la adjudicación

\footnotetext{
7 Soler e Iglesia, 2020. Para los criterios de identificación de los documentos por archivo y signatura véase el apéndice de fuentes.

8 Por ejemplo, entre otros muchos: Calvo, 1998, 2010; Otero, 2007; Nieto, 1995; Romero, 1994; Bahamonde y Otero, 1993; Pérez Yuste, 2004.
} 
por el Estado del servicio telefónico a la CTNE en 1924, a nivel nacional había bastantes redes telefónicas, tanto públicas como privadas. ${ }^{9}$ A partir de esta fecha dio comienzo el proceso de integración de las diferentes redes previas en la CTNE, que prácticamente finalizó a principios de los años 1930 , con las excepciones citadas. ${ }^{10}$ En efecto, las características especiales de los contratos de concesión iniciales de las redes de Guipúzcoa y San Sebastián, y la voluntad de continuidad de sus gestores, fue lo que permitió que mantuvieran su independencia y no se integraran en la CTNE hasta la fecha de su extinción. ${ }^{11}$

La Diputación de Guipúzcoa obtuvo la concesión de la red provincial en noviembre de 1908 por un plazo de 35 años, por lo tanto concluía inicialmente en 1943, pero finalmente la red pasó a integrarse en la CTNE en 1949. Precisamente el retraso se debió al intento en plena guerra, desde 1938, de los gestores de la diputación guipuzcoana de prorrogar la concesión, justificándola por los destrozos en la red ocasionados por la guerra y el esfuerzo inversor consiguiente. El ayuntamiento de San Sebastián obtuvo también la concesión para explotar la red urbana de la ciudad en 1908, pero en 1923 consiguió una prórroga ilimitada, motivo por el cual la red se pudo mantener autónoma hasta 1970, cuando ya pasó a integrase también en la CTNE.

Se hace necesario destacar la personalidad del que fue el alma mater de la RTG, el ingeniero industrial Ignacio María Echaide Lizaosain (1884-1962), Ingeniero Director de la red y responsable directo de la expansión de la misma. Su principal ayudante fue el ingeniero electricista Jenaro Mitxelena Mitxelena (1886-1947) como Jefe de Construcciones e Instalaciones. Ambos fueron los verdaderos impulsores del desarrollo técnico de la red. Las decisiones técnicas, tanto las propias como las asociadas al suministrador principal, Ericsson, eran lideradas por Echaide, asumiéndolas de forma solidaria la Red Municipal de San Sebastián.

La Red Provincial se dividía en ocho zonas, una de las cuales, la del extrarradio de la capital, estaba completamente automatizada. Esto fue posible por disponer de una estructura de conmutación automática con

\footnotetext{
9 Pérez Yuste, 2004, p. 44; Calvo, 1998.

${ }^{10}$ Un estudio de la integración de las redes telefónicas españolas en la CTNE aparece en Gutiérrez, 1997.

${ }^{11}$ Sobre el origen, desarrollo y evolución de las redes de Guipúzcoa y San Sebastián véase: Ibisate, 1998; Gutiérrez, 1997; Echaide, 1923, 1929, 1954.
} 
unidades satélites dependientes de la central de la capital, cuya instalación corrió a cargo de Ericsson. ${ }^{12}$

El interés personal de Echaide por llevar el servicio a las zonas rurales y aisladas, junto con el alto nivel de automatización en la capital y alrededores (con la confluencia del servicio de la red urbana y de la provincial) hizo de Guipúzcoa una provincia con un alto grado de modernización y el de mayor índice de penetración del servicio telefónico en España en los años 1930 , estando a la altura de otras zonas europeas. ${ }^{13}$ Incluso el modelo guipuzcoano se utilizó para el Proyecto de Telefonía Nacional de 1917 de Francos Rodríguez. ${ }^{14}$

En definitiva, antes de la Guerra Civil, existían en Guipúzcoa dos redes telefónicas, la urbana de San Sebastián y la provincial de la Diputación (que además del servicio de conexión a los abonados de los pueblos guipuzcoanos, resolvía el tráfico intraprovincial y la interconexión con la red de la CTNE para el resto del tráfico exterior). Adicionalmente había en la provincia una tercera red sin abonados, exclusivamente interurbana, de la CTNE, que prestaba la interconexión del servicio interprovincial con el resto de España, el interurbano entre San Sebastián, Irún y Tolosa, y el internacional. ${ }^{15}$

Por sus recursos, la red más importante era la provincial, ya que no solo tenía multitud de centrales locales por toda la provincia, sino que operaba la central interurbana de San Sebastián que servía para el tránsito al tráfico intraprovincial y al nacional mediante interconexión manual con la central correspondiente de la CTNE.

La red estaba constituida por ocho zonas: la automatizada dependiente de la capital (San Sebastián), Fuenterrabía, Zarauz, Eibar, Vergara, Azpeitia, Tolosa y Villafranca. ${ }^{16}$ Cada una disponía de una central cabecera de la que dependían las subcentrales de los diferentes pueblos.

12 Ericsson, 1926.

13 En Acta 97 CTDG 3-11-1939 (AGG096, AGG-GAO-JDIT940-A2) aparece estudio comparativo por países. Véase también Aizpuru, 1986, pp. 19-20. Para la notación empleada de las referencias de archivos véase Apéndice 1.

14 Bahamonde y Otero, 1993, p. 207.

15 Echaide, 1929, pp. 4-5. El tráfico interurbano, entre San Sebastián, Irún y Tolosa, gestionado por CTNE, lo era por las condiciones previas de la concesión de 1908 con la Compañía Peninsular de Teléfonos, empresa que absorbió la CTNE con la concesión del monopolio.

${ }_{16}$ Nos referimos, respectivamente, a Hondarribia, Zarautz, Eibar, Bergara, Azpeitia, Tolosa, Orditzia. Esta última anteriormente Villafranca de Ordizia, o simplemente Villa- 
En cada zona, además de la central cabecera, había varias secundarias. Para establecer comunicación desde las secundarias con otra central normalmente se hacía a través de la cabecera de zona, pero en los casos de proximidad había enlaces directos entre secundarias.

Las conferencias con otras provincias se establecían a través de la central interurbana manual de la CTNE en San Sebastián, aunque también había enlaces con Vizcaya desde la central de Azpeitia y con Álava desde la de Vergara. Las conexiones internacionales se establecían por la red de la CTNE, a través de San Sebastián e Irún hacia Francia. Este detalle sobre las conexiones nos permitirá entender más adelante cómo, durante el periodo de enfrentamientos bélicos en Guipúzcoa, iba variando el control de las diferentes zonas telefónicas según la variación del frente.

La dirección de la RTG estaba constituida, por un lado, por la Comisión de Teléfonos de la Diputación de Guipúzcoa (CTDG), formada por gestores no técnicos, y por otro había una dirección técnica bajo responsabilidad de Echaide, que además participaba en las reuniones de la comisión. ${ }^{17}$

\section{La fase militar de la contienda en Guipúzcoa y su impacto en la red telefónica}

En Guipúzcoa fracasó el Golpe de Estado, en concreto en la capital guipuzcoana las hostilidades duraron entre el 18 y el 23 de julio de 1936, momento en el que las autoridades republicanas se hicieron con el control total de la ciudad. ${ }^{18}$

Uno de los factores de gran importancia para el éxito o el fracaso del golpe en las grandes poblaciones españolas fue el intento de control por ambos bandos de los edificios de teléfonos y telégrafos. En el caso de San

franca. Se deja en el cuerpo del texto el nombre usado en la época para evitar confusiones a la hora de la posible contrastación de fuentes por terceros.

17 En las referencias del AGG no hay que confundir las actas de la CTDG, con las de la Gestora de la Diputación. Esta última trataba todos los temas generales de la Diputación, que incluían, además de teléfonos, asuntos de ferrocarriles, caminos, miqueletes, etc.

18 Aquí se ha seguido Alía Miranda, 2011, para la fase posterior de la guerra en Guipúzcoa: Barruso, 1996; Fusi, 1987; Gutiérrez Arosa, 2007. 
Sebastián, el Gobernador Civil actuó de forma determinante en este aspecto, de tal forma que, desde el Gobierno Civil:

«... se establecía un control severísimo sobre el teléfono automático y sobre las comunicaciones provinciales y se ordenaba al jefe encargado de la Telefónica que, bajo ningún pretexto y bajo su responsabilidad personal y directa, responsabilidad de vida o muerte, no se estableciese ninguna comunicación entre Guipúzcoa y cualquiera otra provincia que no hubiese sido antes concedida por la autoridad legítima, es decir por el gobernador civil...» ${ }^{19}$

Durante los cinco días que duró la lucha en la capital donostiarra, desde el lado republicano «el teléfono funcionó sin descanso buscando el contacto con diversos puntos», pero hubo casos en que, por la intervención de las líneas telefónicas, el enemigo logró localizar la posición de los militares leales desde la que gestionaban la coordinación de las tropas y de las milicias.$^{20}$ En efecto, a lo largo de un informe del lado republicano sobre los acontecimientos en San Sebastián, se concreta la cantidad de conversaciones telefónicas establecidas entre autoridades republicanas y responsables militares para esclarecer quién estaba del lado de los rebeldes. ${ }^{21}$

Una vez iniciada la Guerra Civil, habiendo triunfado la sublevación en Navarra y Álava, los sublevados ${ }^{22}$ establecieron, entre otras, su prioridad en el control de la frontera francesa y de las zonas industriales de Guipúzcoa y Vizcaya.

La campaña en Guipúzcoa duró relativamente poco, centrándose la parte más dura del combate en la frontera. Irún cayó bajo dominio franquista el 5 de septiembre y la capital, San Sebastián, el 13 del mismo mes. El ejército y las milicias republicanos se replegaron hacia Vizcaya, lo-

19 Causa General de la Guerra Civil en Guipúzcoa (AHN025, AHN-FC-CAUSA-GENERAL, 1336, Exp. 2-45, Imagen 45/162).

${ }^{20}$ Ibidem, imagen 57/162, AHN025.

21 Ibidem.

${ }^{22}$ Hasta la constitución del Gobierno de Burgos, hay acuerdo entre los historiadores en denominar el bando franquista, como rebelde o sublevado. Luego una vez ya España con la existencia de dos estados, al autodenominado nacional se le suele llamar nacional o nacionalista (esto es más propio en la historiografía inglesa y norteamericana). Evitamos el término «nacionalista», aunque es correcto por ser «nacionalista español», para evitar confusiones con el nacionalismo vasco. 
grando estabilizar el frente en la zona de Eibar-Elgueta a principios de octubre de 1936, por lo que, para esas fechas, casi toda la provincia estaba en manos de los franquistas. Esta situación duró hasta marzo de 1937, cuando el ejército del general Mola inició la ofensiva hacia Vizcaya, que terminó con la toma de Bilbao el 19 de junio de dicho año. Sucesivamente, los municipios con cabecera telefónica o central secundaria, y en los que por tanto se podía cortar o establecer las comunicaciones con otras zonas, según estuvieran o no en el bando enemigo, fueron pasando del control republicano al nacional, de forma que el 4 de octubre, cuando se estabiliza el frente en la zona de Eibar y Elgueta, los sublevados ya dominaban prácticamente el $95 \%$ del territorio guipuzcoano. Este frente se mantuvo estable hasta finales de abril de 1937, cuando los nacionales tomaron Elgueta y Eibar. Por lo tanto la única central cabecera en manos de los republicanos una vez estabilizado el frente era la propia de Eibar. En Elgueta no había central, solo una estación de servicio público, que dependía de la central de Vergara, en zona nacional, y por lo tanto incomunicada telefónicamente.

El destrozo de la red, considerando su totalidad, es decir centros telefónicos y cables (tanto de líneas de abonados como de enlaces entre centros) fue aproximadamente entre un $30 \%$ y un $40 \%,{ }^{23}$ lo que implicó prolongadas incomunicaciones, que se fueron solucionando paulatinamente. Algunas localidades importantes estuvieron incomunicadas telefónicamente hasta finales de noviembre de $1936 .^{24}$

No todas las incomunicaciones se produjeron por destrozos, algunas lo fueron porque los republicanos, en su huida, directamente desmontaron algunos centros manuales y se los llevaron. ${ }^{25}$

La central que mayores destrozos sufrió fue la de Irún, compuesta por cinco cuadros, que quedó en 1936 completamente inutilizada. ${ }^{26}$ Recorde-

23 Acta 97 CTDG 3-11-1939 (AGG096, AGG-GAO-JDIT940-A2). Informe de 2-111939 sobre el estado de la red provincial desde 1923 (en Expediente Supresión Concierto con el Estado parte 4) (AGG104, AGG-GAO-JDIT1402-69).

24 Acta 1 CTDG 20-11-1936 (AGG002, AGG-GAO-JDIT1113-1); Informe de noviembre 1936 sobre el estado de la red provincial (AGG019, AGG-GAO-JDIT1402-3).

25 (AGG096, AGG-GAO-JDIT940-A2) y (AGG104, AGG-GAO-JDIT1402-6).

26 Explicación de terminología. Centro o central es lugar en donde se concentran las instalaciones telefónicas, siendo la principal la central de conmutación (fuera manual o automática). Cuadro era la denominación genérica del panel en las centrales manuales en el que se concentran las terminaciones de los circuitos de líneas de abonado y enlaces para facilitar su conmutación manual. Puesto o posición era cada uno de las subdivisiones de 
mos que la batalla de Irún fue clave para el desarrollo posterior del conflicto en la provincia. ${ }^{27}$

Otros centros telefónicos que sufrieron desperfectos fueron los de Zarauz, Zumaya, Tolosa y Azpeitia, a los que hay que añadir los casos de Deva, Oñate y Vergara, por desmontaje, parcial en algunos casos y total en otros, de los respectivos cuadros antes de la evacuación de cada localidad. ${ }^{28}$ Fijémonos que de estos siete centros, cuatro eran cabecera de zona, es decir que concentraban la mayor parte de las comunicaciones de cada zona y las interurbanas entre zonas (Fuenterrabía-Irún, Zarauz, Azpeitia y Tolosa).

En el caso de la capital, San Sebastián, los daños fueron menores, principalmente en la red de planta exterior. La única excepción fue la central interurbana de la CTNE, en la que los republicanos hicieron explotar parte de las conexiones del cuadro interurbano, lo que la CTNE, una vez tomada San Sebastián por los sublevados, solucionó con un empalme provisional, restableciendo el servicio. ${ }^{29}$

A continuación, repasemos el impacto de la contienda en el personal de la red, y por tanto también en su capacidad de gestión y explotación. Cuando la toma de San Sebastián, se evacuó al personal de la Diputación, gran parte del cuál fue hacia la zona de Eibar y posteriormente a Bilbao. De hecho, el gobierno de la Diputación guipuzcoana se instaló en Bilbao, donde gestionó los recursos técnicos y humanos que pudo. Lo mismo ocurrió con las diferentes zonas entre San Sebastián y Bilbao, no obstante, en la zona de Fuenterrabía e Irún una gran parte de los empleados de la Diputación pasaron a Francia.

En octubre de 1936 los nacionales ya controlaban todos los centros de la red salvo el de Eibar, siendo la cantidad de personal disponible significativamente reducida. La causa fue la citada evacuación de la población civil por las autoridades vascas según iba avanzando el frente. Parte de los empleados de la red, o bien no quisieron evacuar, por ser partidarios del

los cuadros cuando su tamaño requiere la atención de más de un operador. Cada puesto se atendía típicamente por una operadora telefonista.

27 Acta 12 CTDG 12-3-1937 (AGG012, AGG-GAO-JDIT1113-1). Sobre la destrucción de Irún véase (AHN025, AHN FC-CAUSA-GENERAL,1336, Exp. 2, imágenes 120 121;130-131;135-136).

${ }^{28}$ Los datos particulares de cada caso aparecen en Acta 1 CTDG, 20-11-1936 (AGG002, AGG-GAO-JDIT1113-1) e Informe sobre situación de la Red Telefónica Provincial a noviembre 1936 (AGG019, AGG-GAO-JDIT1402-3).

29 De Salas, 1941, p. 374. 
bando rebelde, o bien no pudieron. El resto se integró en la Diputación en zona republicana o marcharon a Francia; algunos intentaron volver a Bilbao y otros, por diversas circunstancias, se quedaron en el país vecino, principalmente en Hendaya y Bayona. ${ }^{30}$

También hay que considerar la posterior depuración de las autoridades franquistas sobre el personal de teléfonos que permaneció en zona nacional, cuando no había pruebas de lealtad al bando sublevado, depuración que implicaba en muchos casos el cese definitivo como empleado de la red, y en otros la suspensión temporal de empleo. Otro importante factor fue la militarización de parte de los empleados de la Red y su movilización en el ejército. En marzo de 1937, con toda la provincia ya bajo control franquista, se puede afirmar que el personal de la red de teléfonos quedó reducido aproximadamente a la mitad, según valoración de la propia comisión en esas fechas. ${ }^{31}$

La información sobre el número de empleados que hemos podido obtener de forma fiable alcanza hasta el año $1929 .{ }^{32}$ La plantilla la componían entonces unas 240 personas (se mantuvo bastante estable desde 1923, año en el que ya se había producido una gran expansión de la red, por lo que se puede deducir que el número de empleados en 1936 era algo mayor, ya que desde 1926 incluso el número de telefonistas se redujo por la automatización de la capital y su extrarradio). ${ }^{33}$ De estos empleados, algo más de 70 se localizaron en zona republicana o en Francia. ${ }^{34}$

${ }^{30}$ Hay abundantes referencias sobre personal de teléfonos en Francia que escribían a la Diputación (republicana) de Guipúzcoa en Bilbao, por ejemplo, entre otras (CDMH062, CDMH-PS-SAN-A-C0253-EXP0013), (CDMH065, CDMH-PS-SAN-C54-EXP 26), Sesión DR12-1-1937 (AGG-DR005, AGG-GAO-SS328-1).

31 En Acta 12 CTDG 12-3-1937 (AGG012, AGG-GAO-JDIT1113-1) se indica expresamente esta situación, que se puede confirmar después de analizar datos cruzados, no siempre consistentes, de bastantes documentos, tanto de la Diputación en zona republicana (en Bilbao) como en zona nacional. Por ejemplo: Acta 19 DN 16-3-1937 (AGG-DN004, AGG-GAO-JDTL0388); Acta 21 DN 15-4-1937 (AGG-DN005, AGG-GAO-JDTL0388); (AGG-DN031, AGG-GAO-SS328-1) y (AGG-DR014, AGG-GAO-SS328-1).

32 Echaide, 1954.

33 Acta 50 CTDG 5-8-1938 (AGG056, AGG-GAO-JDIT1114-1), Acta DN 19-111940 Propuesta aumento de plantilla (AGG-DN030, AGG-GAO-JDTL0388).

34 Información sintetizada de bastantes actas de la Diputación republicana en Bilbao, donde se iba completando la información, AGG-DR002 a AGG-DR018 (todas con la misma signatura original AGG-GAO-SS328-1). Antes dijimos que el personal operativo se redujo a la mitad aproximadamente, según información de la propia CTDG. Hay que considerar que esos 70 son de los que hay constancia documental que resultaron localizados 
Del personal de la red, merece destacarse el caso de los tres más importantes, por su labor de dirección y gestión técnica, nos referimos a los ya citados Echaide como Director y Mitxelena como Jefe de Instalaciones, además de Santiago Marín como Jefe de Explotación. Los tres acabaron al final en zona nacional, pero tras diversas vicisitudes. Echaide desde el principio, Marín primero en zona republicana, para establecerse en la nacional a partir de junio de 1937 y reincorporarse en su puesto, y por último, Mitxelena que fue encarcelado por las autoridades franquistas y destituido de su cargo.

Echaide, en su condición de católico y conservador, aunque simpatizante con el nacionalismo vasco, se posicionó a favor del bando rebelde, decidiendo esconderse y quedarse en la capital guipuzcoana. ${ }^{35}$ Ahora bien, a esta condición política, se añadía la de ser claramente euskaldún, tanto en defensa de la lengua autóctona, el euskera ${ }^{36}$, como de las instituciones vascas. Probablemente este fuera el motivo de que no tuviera problemas con los milicianos republicanos antes de la caída de San Sebastián, junto con el hecho de que era amigo personal de dos destacados dirigentes socialistas vascos. ${ }^{37}$ Ya antes, entre el 18 de julio y el 13 de septiembre, estuvo trabajando con relativa normalidad en su oficina como ingeniero de la red, según cuenta su propia hija:

Aitatxo no dejó de ir a la oficina. Todos, todos los días iba por las mañanas, a pesar de que era muy arriesgado, porque entonces mataban a cualquiera, no ya por cuestiones políticas, bastaba que fuera un buen cristiano. Pero Aitatxo no dejó de ir un solo día y, gracias a Dios, no le

en zona republicana o en el exilio, al ponerse en contacto con las autoridades republicanas, es decir con la Diputación republicana en Bilbao. El resto, hasta 120 aproximadamente, puede que hubieran muerto, desaparecido, encarcelados en zona nacional, o estuvieran en zona republicana o en Francia pero sin haberse puesto en contacto, y, por tanto, sin constancia documental.

35 Como cuenta su propio hijo Yon (Etxaide Itharte, 1986), Ignacio María Echaide era integrista. Pero hay que entender ese concepto en esos años, integrismo en el sentido puramente moral, como sinónimo de integridad, aunque sí que profundamente conservador.

${ }^{36}$ Desde los inicios de la red, Echaide personalmente asumió la necesidad de que los empleados, especialmente los que atendían al público como las telefonistas y los repartidores, hablaran y escribieran con fluidez tanto castellano como euskera (Etxaide Itharte, 1986; Diputación de Guipúzcoa, 1911, p. 27).

37 Etxaide Itharte, 1986, p. 68 (de la edición original en euskera, nosotros hemos usado un borrador de traducción en castellano realizado por Ana María Echaide, hija de Ignacio María, a quien agradecemos su generosidad). 
pasó nada, ni por parte de los rojos ni tampoco después por parte de las tropas de Franco por haber trabajado con los rojos. Pero procuraba hacer las cosas un poco discretamente. ${ }^{38}$

Todos los miembros de la Junta directiva de la CTDG evacuaron la ciudad, excepto precisamente Echaide (ni Mitxelena ni Marín, pertenecían a la Junta Directiva de la Comisión, aunque a veces participaban en las reuniones de la misma).

En cuanto a Jenaro Mitxelena, estaba en Palencia al comienzo de la guerra y ante las noticias decidió volver precipitadamente a su ciudad natal, Oyarzun, pero fue arrestado y a punto de ser fusilado por las nuevas autoridades, ya que se significó en apoyo del nacionalismo vasco (era Presidente de la Junta Municipal del PNV en Oyarzun ${ }^{39}$ ). En esos momentos críticos, Echaide intercedió ante la máxima autoridad militar en Guipúzcoa, evitando su fusilamiento, ${ }^{40}$ pero se mantuvieron los cargos contra Mitxelena, de los que fue posteriormente absuelto. ${ }^{41}$ Ahora bien, no se llegó a reintegrar en la red telefónica, de hecho fue destituido de su cargo y su plaza como Jefe de Instalaciones se amortizó posteriormente. ${ }^{42}$

Justo después de evitar su fusilamiento, Mitxelena se incorporó a un regimiento de transmisiones del ejército franquista, ayudando a localizar un cable subterráneo de conexión internacional con Francia e indicando dónde era más conveniente efectuar el corte, para incomunicar la zona republicana con el país vecino. Posteriormente, montó un modelo de cuadro telefónico manual, con el que luego construyó veintisiete más, para su uso por

38 «Aitatxo» es «Papá» en euskera. Este texto es una narración de María Isabel Echaide a su hermana Ana María, ambas hijas de Echaide, y transcrita por esta última.

39 (CDMH067, CDMH-PS-BILBAO Caja 251, expdte7).

40 Etxaide Itharte, 1986, pp.195-200. En el Consejo de Guerra que sufrió Mitxelena, el general Solchaga intercedió en su favor. Véase Tribunal Nacional de Responsabilidades Políticas (CDMH068, CDMH-75/00590).

41 Tribunal Nacional de Responsabilidades Políticas, Indultados, Expediente Genaro Michelena (sic), (CDMH068, CDMH 75/00590); BOE 06/05/1937, p.1297; BOE, 28/03/1940, p. 1605.

${ }^{42}$ No hemos encontrado ningún documento en el que oficialmente se indique la destitución de Mitxelena, pero en varios documentos aparece la amortización de dicha plaza, Acta 1 DN 21-1-1938 (AGG-DN011, AGG-GAO-JDTL0388); Acta 12 CTDG 12-3-1937 (AGG012, AGG-GAO-JDIT1113-1). Por otra parte la CTDG insistía ante la Diputación sobre la necesidad de asignar esta plaza, Acta 14 DN 1-7-1938 (AGG-DN016, AGGGAO-JDTL0388). Al respecto, la familia Mitxelena Rekalde recuerda que sí volvió a trabajar en la Red de Guipúzcoa. 
el ejército nacional. Además, como miembro movilizado, ayudó de forma determinante a restaurar las líneas y equipos deteriorados por la guerra. ${ }^{43}$

Por último, Santiago Marín jugó a ambas cartas con los bandos en conflicto. A finales de julio de 1936, Marín fue arrestado por las autoridades republicanas en su domicilio de Oñate, por las sospechas que recayeron sobre él al ordenar a una vigilante de tráfico que todas las conferencias pasasen por vía Mondragón, en vez de por Vergara. Respecto a su caso se afirmaba:

«esta medida obedeció sin duda a que la línea de Vergara estaba controlada por personal afecto al régimen republicano», [y se subraya que] «además sobradamente son conocidas por todos los que hemos actuado en la vida pública, las simpatías de dicho señor por los dirigentes propulsores de este movimiento que está desangrando a nuestra nación». ${ }^{44}$

Posteriormente, Marín fue encarcelado y trasladado a Bilbao, donde fue puesto en libertad en noviembre de 1936 «por no probarse que se hubiera significado contra el régimen» (republicano). ${ }^{45}$ Más tarde, en junio de 1937, con la orden de evacuación del personal de la Diputación guipuzcoana en Bilbao hacia Santander, cuando las tropas nacionales ya estaban a las puertas de la capital vizcaína, Marín desoyó dicha orden y decidió quedarse, volviendo así a estar bajo el bando nacional. Sabemos con seguridad que en octubre de 1937 ya estaba reincorporado, como Jefe de Explotación, en la Red de Guipúzcoa en zona nacional. ${ }^{46}$

\section{La gestión de la red en zona republicana ${ }^{47}$}

Tras la evacuación de la capital donostiarra, la Diputación republicana se estableció primero en Motrico el 15 de septiembre de 1936 y luego en

${ }^{43}$ Esta información es testimonio tanto del propio Mitxelena, como de Echaide y de mandos militares nacionales, en sus alegaciones en noviembre de 1939 contra la multa impuesta por responsabilidades políticas al pertenecer al PNV (CDMH068, CDMH 75/00590).

44 Sesiones Diputación republicana en Bilbao (DR) 1-12-1936 y 3-12-1936 (AGGDR004, AGG-GAO-SS328-1).

45 Sesiones DR 1-12-1936 y 3-12-1936 (AGG-DR014, AGG-GAO-SS328-1).

46 Acta 27 CTDG 22-10-1937 (AGG013, AGG-GAO-JDIT1113-1).

$47 \mathrm{La}$ información que hemos podido obtener es escasa, hay que considerar que la gestión de la red provincial por parte de la Diputación republicana se limitó en el tiempo solo hasta mediados de septiembre 1936, salvo la zona de Eibar que fue hasta marzo de 1937. 
Bilbao el 8 de octubre. Se pueden distinguir dos fases en la gestión de la red por la diputación republicana: la primera desde julio de 1936 a principios de octubre del mismo año, donde dicho control se iba reduciendo según el avance de las tropas franquistas; la segunda fase, desde octubre de 1936 hasta marzo de 1937, cuando solo se controlaba la central cabecera de zona de Eibar, con el frente estabilizado en esa zona. Después de marzo de 1937 ya toda la red quedó bajo control de la Diputación nacional.

La primera fase se caracterizó por el intento de control de las comunicaciones desde las centrales manuales, de tal forma que a las telefonistas se les prohibía establecer conferencias con zonas controladas por los sublevados. El Gobierno Vasco ordenó la militarización de industrias con finalidad de guerra e intervino todos los servicios de la CTNE. ${ }^{48}$ Esta reglamentación era congruente con la del Gobierno de la República, quien decretó la militarización de todos los servicios de las grandes empresas, incidiendo especialmente en el caso de la CTNE, asumiendo el mando el Delegado del Ministerio de la Guerra en la empresa. En concreto, se estableció la necesidad del control de las conexiones entre las líneas civiles y las de los cuerpos de transmisiones del ejército. ${ }^{49}$ Ahora bien, una cosa es la legislación, y otra la realidad de los hechos, ya que los Comités de Control Obrero en la CTNE controlaban realmente en muchas zonas las instalaciones de líneas, que se gestionaban, no mediante orden taxativa de mando directa, sino por solicitudes que podían atender o no según situaciones particulares, $\mathrm{y}$, por tanto, sin un control directo por parte de las autoridades republicanas, todo lo contrario que en zona nacional, como veremos más adelante. ${ }^{50}$

48 BOPV, 18-10-1936; BOPV, 26-11-1936.

49 Gaceta de Madrid n. ${ }^{\circ}$ 304, 30/10/1936, página 543.

50 A lo largo de este trabajo se citan diferentes fuentes documentales que reflejan esta situación en zona nacional sobre la RTG, parece factible pensar que se aplicaron los mismos criterios en la CTNE bajo zona franquista. En cambio, para la zona republicana, al no haber existido prácticamente gestión de la RTG no hay ejemplos concretos, pero respecto a documentos del archivo histórico de la CNT (Confederación Nacional del Trabajo) sí hay varios ejemplos del control por los Comités Obreros para la gestión de pedidos de instalaciones a la CTNE por parte del ejército y/o autoridades republicanas que indican una total falta de efectividad en las tramitaciones. Por ejemplo los siguientes: (ACNT005 a ACNT008; Sig48D3-Rollo124). También en CDMH los siguientes: CDMH009 a CDMH014, CDMH-PS-SAN-C0023-EXP0012. 
Siguiendo con el caso que nos ocupa, la RTG, con carácter general se suspendió el servicio de conferencias para el público, para de esta forma poder controlar mejor las correspondientes autorizaciones. De hecho, establecer alguna conferencia no autorizada generaba sospechas de que no se era afecto a la República, como ya hemos visto en el caso de Santiago Marín.

Hay que considerar que en la zona automatizada, San Sebastián y alrededores, no se podía establecer este control si no era desconectando los cables que interconectaban dos zonas, pero, a su vez, las llamadas desde la capital guipuzcoana y el extrarradio (automatizado) con otras zonas de la provincia o con otras provincias, siempre requerían encaminarse por un cuadro interurbano, que era manual, bien por la propia Red Provincial (para llamadas intraprovinciales), o la de la CTNE (para llamadas interprovinciales). En estos casos sí era fácil controlar el establecimiento de las conferencias.

En ocasiones, según se iba perdiendo territorio, las autoridades republicanas ordenaban el desmontaje de los cuadros manuales para su traslado y reutilización. Ahora bien, desmontar un cuadro de forma tal que pudiera reutilizarse posteriormente no era algo trivial, por lo que requería la labor de personal técnico de la red. En referencia a los daños causados en la retirada de las tropas republicanas en las instalaciones telefónicas, un ingeniero de la CTNE realizó en 1941 un extenso trabajo de recopilación de desperfectos en las redes telefónicas a nivel nacional, incluyendo los casos de Guipúzcoa, donde hizo referencia a «la voladura de la de San Sebastián [la interurbana de la CTNE] ... y los desmontajes de infinidad de centros más pequeños y los sabotajes...». ${ }^{51}$

En la segunda fase, desde octubre de 1936, el control se limitó al centro telefónico de Eibar y a la gestión del personal que se presentó en Bilbao o que estaba en Francia.

En el caso de Eibar, hay que considerar, según la estructura de la red, que las comunicaciones con el resto de la provincia y con otras provincias del Estado nacional estaban lógicamente cortadas, ya que la conexión se debía realizar por Azpeitia o San Sebastián, zonas controladas por los nacionales. No obstante, desde unos años antes del conflicto disponía de enlaces directos con Vizcaya, lo que sin duda permitió la comunicación con aquella área.

51 De Salas, 1941. Un resumen muy amplio de esta referencia aparece en «Vicisitudes del Teléfono en la Guerra Civil Española» (https://historiatelefonia.com/2014/09/01/). 


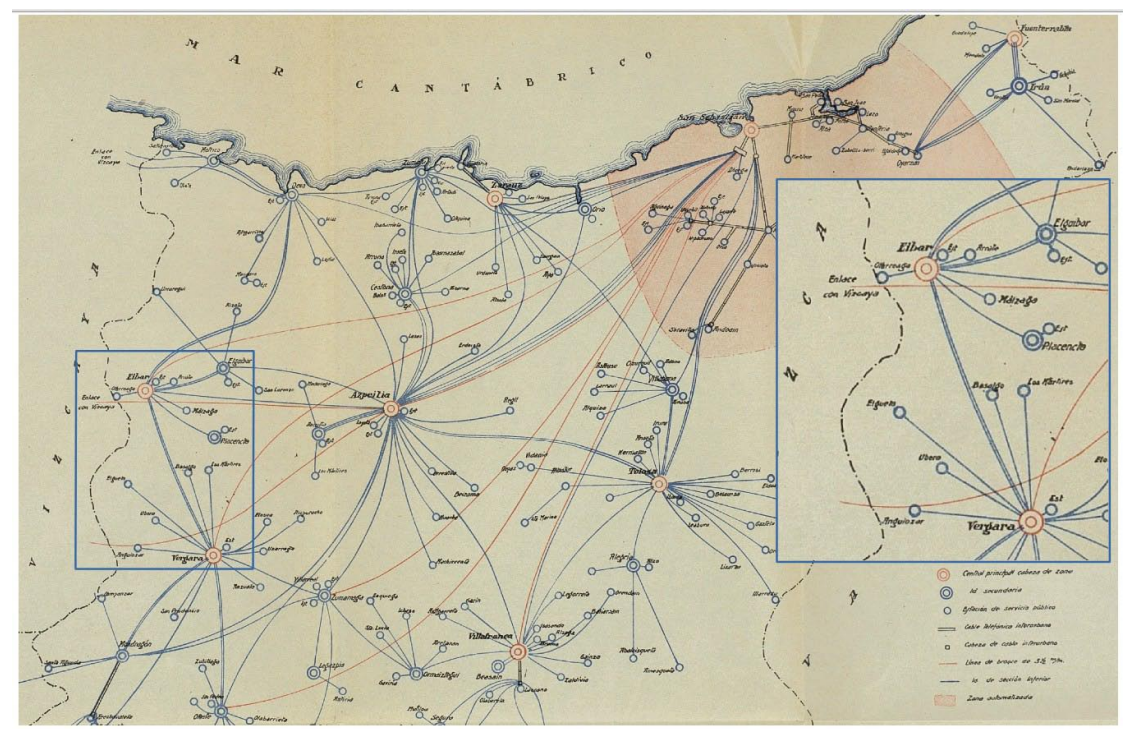

\section{Figura 1}

Conexiones de la central de Eibar

Fuente: Echaide, 1929, p. 29

Efectivamente, si nos fijamos en el esquema de la red de la zona de Eibar (figura 1), esta población tenía ya en 1935 conexión directa con Bilbao y la población vasca de Marquina, por las que pudo mantener comunicación durante el periodo de octubre 1936 a marzo 1937 en el que esta área estaba aún en manos de la República. Sea como fuere, es seguro que el centro telefónico de Eibar estuvo en funcionamiento y que se emplearon estas interconexiones de Eibar con centros de la CTNE en Vizcaya. ${ }^{52}$

Otro aspecto de gestión de la Diputación guipuzcoana en Bilbao fue el control de la plantilla, dispersa inicialmente tras la evacuación de San Sebastián el 12 de septiembre. Una las primeras labores de la Comisión Gestora fue la confección de la relación de personal afecto a la República, no

52 Hay constancia documental de su uso, por ejemplo: acta 22-10-1936 (AGG-DR003, AGG-GAO-SS328-1); Asuntos de personal de teléfonos de la Diputación de Guipúzcoa en Bilbao (AGG-DR015, AGG-GAO-SS328-1) y (AGG-DR016, AGG-GAO-SS328-2). 
solo en lo relativo a la red telefónica, sino a todo el personal de la Diputación. ${ }^{53}$

Al menos doce de los varones empleados en la RTG presentados en Bilbao fueron movilizados por el ejército de la República entre septiembre de 1936 y junio de 1937. La mayoría fueron asignados al Batallón de Enlaces y Transmisiones por su conocimiento de los «servicios de comunicaciones». A otros se les destinó en la Diputación de Vizcaya. ${ }^{54}$

En definitiva, la gestión de la red telefónica en la zona republicana durante este corto periodo se limitó, por un lado, al mantenimiento del servicio en la zona de Eibar priorizando las comunicaciones militares por la contienda; y por otro, en el intento de conservar el control de la estructura y la organización de la empresa, desde una Diputación itinerante, con el objetivo - en vano- de posibilitar su restauración una vez se hubiese superado la crisis.

\section{La gestión de la red en la zona franquista}

La CTDG se reunía periódicamente para seguir la evolución de la red, cuantificar los servicios usados por los abonados, aprobar los presupuestos para obras de ampliación, establecer los concursos de suministro con los correspondientes suministradores o tratar asuntos de personal. Antes de la guerra se produjo la última sesión el 9 de julio de 1936, no volviéndose a reunir hasta noviembre de 1936, ya bajo control de los sublevados, excepto la zona de Eibar que controlarían desde marzo de 1937.

La Junta Directiva de la red provincial cambió completamente, pero se mantuvieron dos de los responsables directos de la red, Echaide como Ingeniero Director y Marín, como Jefe de Explotación. ${ }^{55}$

Dos fueron los principales asuntos que caracterizaron el inicio de la gestión de las redes telefónicas por parte de las autoridades franquistas: primero, el proceso de militarización y control de las comunicaciones, al

${ }^{53}$ Relación de personal de Teléfonos en la Diputación en Vizcaya (AGG-DR14, AGG-GAO-SS328-1). Además, en sesión 3-6-1937 (AGG-DR007, AGG-GAO-SS328-1) se analizaban los casos de depurados en el bando nacional que aparecían en la prensa franquista (La voz de España, 14-5-1937).

54 Acta 46 CTDG 27-6-1938 (AGG052, AGG-GAO-JDIT1114-1), Acta 11 Diputación 21-1-1938 (AGG-DN011, AGG-GAO-JDTL0388).

55 Acta 1 CTDG 20-11-1936 (AGG002, AGG-GAO-JDIT1113-1). 
que iría asociado el de la depuración del personal; segundo, la reconstrucción de la red y la rehabilitación del servicio.

\subsection{Procesos de militarización, depuración del personal y control de las comunicaciones}

Una de las primeras consecuencias de la guerra en la gestión de la red fue su control por las autoridades militares. El Gobierno de Burgos creó la Dirección General de Comunicaciones para centralizar los servicios telegráficos, telefónicos y postales. ${ }^{56}$ En realidad se produjo una militarización general de todo el sector industrial en la zona controlada por los sublevados, igual que en zona republicana, de la que no fue una excepción el personal de las redes telefónicas. ${ }^{57}$

En efecto, todo el personal estaba militarizado y el masculino estaba especialmente controlado por la Comandancia del Estado Mayor, teniendo que llevar siempre brazaletes identificativos. Además, las autoridades militares realizaron gestiones para situar a personas afines en puestos específicos de especial confianza. Así, por ejemplo, el Comandante Militar de Vergara ordenó nombrar a una telefonista, inspectora general de teléfonos del distrito de Vergara, por ser de su confianza, ya que:

«... por la gran importancia que tiene en todo tiempo el tener controladas las comunicaciones telefónicas, que constituye una imperiosa necesidad en tiempo de guerra y, sobre todo, en pueblos fronterizos con la línea de fuego.» ${ }^{58}$

Respecto a este caso, Echaide realizó las gestiones oportunas con algunas reticencias, por problemas derivados del escalafón de la persona asignada, aceptando finalmente que el Mando Militar tenía «ilimitada autoridad» para hacer lo que estimara conveniente..$^{59}$ p. 74 .

56 Boletín Oficial de la Junta de Defensa Nacional de España n. ${ }^{\circ}$ 19, de 10/09/1936,

57 En Apraiz et al., 2016, se proporciona información general sobre el proceso de militarización de las industrias en ambos bandos.

58 Acta 9 CTDG, 29-1-1937 (AGG09, AGG-GAO-JDIT-1113-1).

59 Ibidem. Más casos similares, entre otros muchos, por ejemplo, en Actas CTDG 2011-1936 y 30-12-1936 (AGG002 y AGG008, AGG-GAO-JDIT-1113-1). 
El control militar implicaba que se necesitara autorización expresa de los mandos para la aprobación de los turnos de trabajo del personal, especialmente en los cuadros manuales para llamadas interurbanas ${ }^{60}$, para trabajos concretos de adecuación y mejora de la red, así como de la instalación de líneas. ${ }^{61}$ Además, se producían negociaciones entre la autoridad militar y la dirección de la red para eximir a algunos empleados de su movilización al frente por la importancia de su labor en la red telefónica, así como para que pudiera reincorporarse a la plantilla personal inicialmente depurado pero que posteriormente no sufrió sanción. ${ }^{62}$

Otro aspecto importante era el mantenimiento del secreto de las comunicaciones. Todo esto implicaba mucha tensión de los operarios de cuadros manuales ante la disyuntiva de autorizar o no las conferencias según la identificación del llamante, ya que tenían orden de no atender ninguna conferencia que no fuera de las líneas de las autoridades militares convenientemente identificadas. ${ }^{63}$

Estas limitaciones en el establecimiento de conferencias, así como el de las franquicias a organismos oficiales, implicaba una gran reducción de los ingresos de la red provincial, ya que las llamadas con intervención de operadora suponían una importante fuente de ingresos, al ser el resto por abono. La situación en cuanto a la hora de permitir o restringir llamadas, o de permitir nuevos abonos, era ciertamente caótica, de tal forma que los directivos de la red provincial hicieron una propuesta a la Autoridad Militar para unificar criterios en relación con el servicio telefónico, con el objeto de proporcionar mayores facilidades a la hora de instalación de abonos, y así:

60 Acta 8 CTDG, 16-1-1937 (AGG010, AGG-GAO-JDIT-1113-1).

61 Entre otras, por ejemplo, carta del 27-9-1938 de la CTDG a la Comisión Provincial (AGG073, p. 13, AGG-GAO-JDIT1114-1) sobre la necesaria autorización del Gobierno Militar para el estudio y el dibujo de planos asociados a los proyectos de canalización y replanteo de líneas en varias localidades.

62 Por ejemplo, Propuestas CTDG 1938 (AGG113, AGG-GAO-JDIT1114-2); Acta 67 CTDG 30-12-1938 (AGG073, AGG-GAO-JDIT1114-1).

${ }^{63}$ Hubo muchos casos concretos con sanciones y confusión por estos motivos, por ejemplo: Acta 3 CTDG, 4-12-1936 (AGG004, AGG-GAO-JDIT1113-1); «Expediente por avería de teléfono en el Faro de Fuenterrabía, 20-11-1936 (AGG071, AGG-GAOJDIT1114-1); para más casos véase Soler e Iglesia, 2020. 
Pablo Soler Ferrán, José Ramón Iglesia Medina

«... se consienta a los abonados hablar desde sus domicilios sin perjuicio de realizar la más escrupulosa censura de las conferencias por medio de los censores que las escuchan». ${ }^{64}$

Uno de los asuntos más delicados fue el de autorizar o no las franquicias telefónicas solicitadas por multitud de organismos, tanto civiles como militares, asociados a las autoridades franquistas ${ }^{65}$ Esto implicó multitud de gestiones respecto a las peticiones y delicadas negociaciones, aunque normalmente la Diputación se veía obligada a autorizar dichas franquicias. ${ }^{66}$

Por otra parte, el proceso de militarización afectó lógicamente a las relaciones laborales, lo que implicó, en el caso de la red provincial, la modificación del Reglamento de Régimen Interior, vigente desde 1932, del que se afirmaba:

«... influido por el espíritu netamente marxista que entonces imperaba, descuidó de modo manifiesto los intereses de la Provincia y de la Corporación y sólo se cuidó de lo que pudiera favorecer materialmente al empleado y de relajar la disciplina del personal.» ${ }^{67}$

Otro aspecto del control militar fue la cesión de equipos de la propia red provincial al Ejército Nacional, lo que mermó la propia capacidad de gestión técnica. No solo se entregaron repuestos y elementos, como pilas, cables, indicadores y clavijas, sino también vehículos y cuadros telefónicos completos (es decir centrales de conmutación manuales) ${ }^{68}$ Esto im-

64 Acta CTDG 22-10-1937 (AGG013, AGG-GAO-JDIT1113-1).

65 El Gobierno de Burgos publicó bastantes órdenes y decretos sobre franquicias telefónicas para gran variedad de organismos oficiales, otros adscritos a Falange, y para el ejército. La primera Orden fue la publicada en el BOE, n. ${ }^{3}$ 15/10/1936, p. 10.

${ }^{66}$ Hay gran variedad de casos con constancia documental, los más significativos, por ejemplo Actas 47 y 57 CTDG 8-7-1938 y 30-091938 (AGG053 y AGG063, AGG-GAOJDIT1114-1); para más casos véase Soler e Iglesia, 2020 (en varias se trataba el problema de ingresos que generaba el alto número de franquicias por la situación de guerra). Se llegó a hacer un listado completo de franquicias con la intención de no autorizar más que las estrictamente justificadas, Acta 71 CTDG 24-2-1939 (AGG055, AGG-GAO-JDIT1114-1).

${ }^{67}$ Actas 8 y 9 DN, 10-12-1936 y 24-12-1936 (AGG-DN002 y AGG-DN003, AGGGAO-JDTL0388); Sobre la modificación de dicho reglamento se debatió ampliamente en la CTDG (AGG003, AGG005 y AGG006, AGG-GAO-JDIT1113-1).

68 Actas 8 y 12 CTDG 16-1-1937 y 12-3-1937 (AGG010 y AGG012, AGG-GAOJDIT1113-1), también actas 52 y 55 CTDG 19-8-1938 y 16-9-1938 (AGG058 y AGG061, AGG-GAO-JDIT1114-1). Para mayor información sobre este tema véase Iglesia y Soler, 
plicó ya a finales de la guerra una delicada gestión por parte de la Diputación para la devolución de dichos equipos. ${ }^{69}$

En cuanto a la depuración de personal se produjo en dos fases: una primera, desde diciembre 1936 a abril 1937, en aplicación del decreto de control de funcionarios públicos ${ }^{70}$ de forma global para todo el personal que no se presentó en sus puestos de trabajo en zona nacional; y una segunda paulatina, ya de forma individualizada, respecto del resto del personal, mayoritariamente por simpatizar o pertenecer al PNV. ${ }^{71}$ De la misma forma, se hacía un análisis de la idoneidad del personal de nuevo ingreso que sustituía a los depurados, así como un seguimiento especial a personal incorporado durante el período del Frente Popular. ${ }^{72}$

En definitiva, la unidad de mando que caracterizó a la zona nacional, tanto en lo civil como en lo militar, se ejerció también en la gestión de la RTG. Es conocida que esta circunstancia fue una de las causas del resultado final de la guerra, frente a las dificultades en la zona republicana para ejercer dicha unidad (los enfrentamientos internos en el lado republicano entre anarquistas y comunistas, así como las dificultades impuestas por los Comités de Control Obrero a las autoridades republicanas). Para el caso de la RTG hemos comprobado que en la zona nacional hubo un férreo control militar de las redes telefónicas, por ejemplo las peticiones de instalación de líneas se tramitaban como órdenes militares de obligado cumplimiento. En cambio, en zona republicana, ya hemos indicado que no se produjo.

2017, donde se analiza, además del caso de la red de Guipúzcoa y Ericsson, el suministro de equipos de telecomunicaciones al ejército franquista a nivel nacional por parte de otras operadoras como la CTNE y la Red Urbana de San Sebastián, así como de empresas europeas.

69 Actas 74 y 76 CTDG 24-3-1939 y 28-4-1939 (AGG058 y AGG060, AGG-GAOJDIT1114-1).

70 Decreto n. ${ }^{\circ} 93$ de 3-12-1936, BOE, 9-12-1936, n. ${ }^{\circ}$ 51, p. 354.

71 En los fondos del AGG hay multitud de documentos con casos particulares individualizados, por ejemplo, entre otros muchos, Acta Comisión Gestora Diputación de Guipúzcoa 1-4-1939 (AGG-DN-023, AGG-GAO-JDTL0388). Para más casos véase Soler e Iglesia, 2020. Este aspecto, un estudio detallado del proceso de depuración en el personal de Teléfonos, no es el objeto de este trabajo, que requiere un análisis específico sobre el tema. Al respecto hay investigaciones sobre la depuración en la Diputación de Guipúzcoa (Buces y Querejeta, 2016; Barruso, 2005).

72 Por ejemplo en Actas 43 y 45 CTDG 3-6-1938, 17-6-1938 (AGG049 y AGG051, AGG-GAO-JDIT1114-1) y Acta 65 CTDG 16-12-1938 (AGG071, AGG-GAOJDIT1114-1). 


\subsection{Tareas de reconstrucción y mejora de la red}

La nueva Diputación, al asumir la gestión de la red telefónica provincial, evaluó el estado de la red, comprobando los daños ocasionados en los diferentes centros e identificando aquellos en los que el servicio se vio afectado total o parcialmente. En la medida de lo posible, se iniciaron los trabajos de reparación para, en algunos casos, restablecer el servicio cuando había incomunicación total (como ocurrió en varias localidades) y, en otros, mejorar su calidad intentando recuperar los niveles estándares anteriores al conflicto ${ }^{73} \mathrm{El}$ servicio quedó restablecido en su mayoría a mediados de noviembre de 1936, en muchos casos con una capacidad inferior a la inicial, ya que, cuando había más de un cuadro inhabilitado, la reparación del centro se acometía solo parcialmente. ${ }^{74}$

Evidentemente, todos estos trabajos de mejora de la red iban asociados a los presupuestos disponibles. Los de 1937 se constata que eran de crisis, caracterizados por la situación de guerra y por los intentos de rehabilitación de centros destruidos. ${ }^{75}$ Poco a poco la situación fue mejorando y desde finales de 1938 los presupuestos empezaban a estar más acordes con lo normal en la gestión de una red telefónica ${ }^{76}$ De hecho, desde mediados de 1938 hubo una cierta bonanza económica de la zona, en comparación con otras zonas de España. ${ }^{77}$ En síntesis, a raíz del control de Vizcaya por los nacionales, unido al control anterior de Guipúzcoa y la frontera francesa, hubo un relativo auge económico e industrial en Vizcaya y Guipúzcoa. Esto fue gracias principalmente al apoyo al bando sublevado por parte de sectores bancarios e industriales relevantes, y la au-

73 Informe sobre la situación de la red en noviembre 1936 (AGG019, AGG-GAOJDIT1402-3).

74 Acta 1 CTDG 20-11-1936 (AGG002, AGG-GAO-JDIT1113-1); Informe sobre situación de la red, 20-11-1936 (AGG019, AGG-GAO-JDIT1402-3).

75 Acta 6 CTDG, 18-12-1936 (AGG007, AGG-GAO-JDIT1113-1) y proyecto de presupuesto para 1937 (AGG009, AGG-GAO-JDIT1113-1). Este aspecto está relacionado con los problemas de escasez de material (AGG067 y AGG069, AGG-GAO-JDIT1114-1).

76 Acta 65 CTDG 16-12-1938 (AGG071, AGG-GAO-JDIT1114-1).

77 Apraiz et al., 2016, señalan el paulatino auge industrial en Guipúzcoa después del control de Vizcaya por las tropas de Franco. Extendiendo el análisis a todo el País Vasco, González Portilla, 1987, establece una conclusión similar respecto a la industria siderúrgica y minera, así como cierto auge económico, plasmado por el aumento significativo de la compra-venta de valores bursátiles de Bilbao desde abril de 1938. 
sencia de boicot de sus homólogos europeos. Nos referimos, en el caso que nos ocupa, a las empresas de telecomunicaciones alemanas, lo que no es sorprendente, pero también, y esto fue fundamental, a la empresa sueca Ericsson.

\subsection{Dificultades en la gestión}

Una de las principales dificultades fue la escasez de personal, que se debió a diversos motivos, en unos casos porque hubo empleados que huyeron a zona republicana, en otros casos por ser destituidos (procesos de depuración) y en otros por estar movilizados al servicio del ejército nacional. ${ }^{78}$ El mismo Echaide se quejaba de «las condiciones deplorables en que se halla respecto al personal masculino en la Red». ${ }^{79}$ La CTDG utilizó este argumento para justificar la necesidad de cubrir la plaza de Jefe de Instalaciones y de otros puestos. ${ }^{80}$

Otro problema fue el de los concursos para dotar nuevas plazas, en los que una de las condiciones para presentarse era estar libre de obligaciones militares. Esto, en situación de guerra, complicaba mucho la resolución de las convocatorias. ${ }^{81}$ Así, en septiembre de 1938 la CTDG solicitó a las autoridades que se replantease la incorporación a filas de personal de la red por ser muy escaso el dedicado a labores técnicas de mantenimiento e instalación, ya que eran necesarios para las canalizaciones y replanteos de líneas de diversas zonas destruidas por la guerra. ${ }^{82}$

En cuestiones económicas, el principal problema fue la anulación del Concierto Económico del Estado con la provincia ${ }^{83}$, aspecto de especial trascendencia que afectó de forma directa al límite de la concesión y la retrocesión de la red. Pero hubo otros factores relacionados con la

78 Entre otros, Acta 66 CTDG 23-12-1938 (AGG072, AGG-GAO-JDIT1114-1) .

79 Acta 12 CTDG 12-3-1937 (AGG012, AGG-GAO-JDIT1113-1).

80 Actas 51 y 56 CTDG 12-8-1938 y 23-9-1938 (AGG057 y AGG062, AGG-GAOJDIT1114-1).

81 Carta 4-3-1938 en Propuestas CTDG 1938 (AGG112, AGG-GAO-JDIT1114-2).

82 Propuestas CTDG 1938 (AGG112, AGG-GAO-JDIT1114-2).

83 Decreto Ley 23-6-1937 Cese Concierto con Diputaciones de Guipúzcoa y Vizcaya (BOE 24-6-1937). Este hecho, y el cómo afectaba a la red, fue analizado de forma exhaustiva por la CTDG durante bastantes sesiones, especialmente respecto a la prórroga de la concesión, como se comprueba más adelante. 
disminución de la facturación, uno de ellos la gran cantidad de abonados morosos por condiciones específicas del conflicto o facturas emitidas en el periodo del Frente Popular.

Otra dificultad fue la gran cantidad de franquicias telefónicas con multitud de organismos oficiales de las autoridades franquistas, tanto civiles como militares, e incluso particulares de índole política asociados a Falange o a los Requetés. ${ }^{84}$ La situación era caótica por la ambigüedad en la aplicación concreta de la legislación asociada a los teléfonos oficiales, en cuanto al carácter supuestamente oficial de muchos abonados. Este mismo asunto generaba conflictos en la facturación mutua entre la red provincial y la CTNE, lo que implicaba una difícil negociación por la realización de conferencias interprovinciales a través de la CTNE y su forma de facturarlas. ${ }^{85}$ Uno de los motivos para no conceder nuevas líneas con franquicia era la ausencia de material. ${ }^{86}$

En general, estas situaciones ocasionaban negociaciones con la directiva de las otras dos redes, la de la CTNE y la urbana municipal, para coordinarse con el objeto de afrontar problemas comunes, como el de los morosos o el de las franquicias. ${ }^{87}$

Hubo casos particulares de gestión técnica compleja, como petición desde organismos militares de centralización de líneas y conferencias para control de la censura, ${ }^{88}$ lo que implicaba el uso de líneas compartidas mediante un conmutador individual ${ }^{89}$ Esta última solución se basaba en una patente de Echaide y Mitxelena de aplicación para líneas lejanas en telefonía rural. ${ }^{90}$

Por ultimo, el problema de la falta de material se veía acrecentado por las dificultades en la importación, ya que a veces se denegaba el permiso para la reserva de las divisas necesarias. Esto implicaba negociaciones

${ }^{84}$ Por ejemplo Acta 64 CTDG 9-12-1938 (AGG070, AGG-GAO-JDIT1114-1).

85 Actas 49, 60 y 68 CTDG 27-7-1938, 25-10-1938 y 13-1-1939 (AGG055 y AGG066, AGG-GAO-JDIT1114-1; AGG074, AGG-GAO-JDIT940-A2).

${ }^{86}$ También este problema aparece de forma reiterada a lo largo de la documentación primaria, por ejemplo, entre otros Acta 40 CTDG 21-4-1938 (AGG044, AGG-GAOJDIT1114-1). Más casos en Soler e Iglesia, 2020.

87 Acta 77 CTDG 12-5-1939 (AGG083, AGG-GAO-JDIT914-A2).

88 Acta 44 CTDG 10-6-1938 (AGG050, AGG-GAO-JDIT1114-1).

89 Actas 47 y 53 CTDG 10-6-1938 y 26-8-1938 (AGG053 y AGG059, AGG-GAOJDIT1114-1).

90 Conmutador automático para estaciones telefónicas. Patente n. ${ }^{\circ} 66243$ de 19 enero 1919, Archivo Histórico de la Oficina Española de Patentes y Marcas. 
con el Ministerio de Industria para justificar detalladamente la necesidad de dicha importación. ${ }^{91}$

\subsection{El papel de Ericsson y otras empresas suministradoras de equipos ${ }^{92}$}

En cierto modo la trayectoria de la RTG no se puede deslindar de la de Ericsson, ya que la empresa sueca fue la principal suministradora de la red. Ericsson tenía desde antes de la Guerra Civil una división en España, denominada Compañía Española Ericsson (CEE), con sede central y fábrica en Getafe (Madrid), y una delegación comercial en Barcelona. Las instalaciones de Getafe fueron incautadas por el gobierno republicano, estableciéndose como fábrica de material de guerra, y la matriz sueca perdió todo control sobre su única fábrica en España. De esta forma la dirección de la empresa sueca decidió crear una delegación en San Sebastián, una vez ya en zona nacional, que en la práctica era el centro de sus operaciones en España, ya que la delegación de Barcelona se había cerrado anteriormente. ${ }^{93}$

Ericsson, bajo una apariencia de neutralidad, no dudó en ningún momento en ponerse del lado de los sublevados al suministrar equipos a las redes civiles telefónicas de Guipúzcoa y San Sebastián. ${ }^{94}$ Por otro lado, su hombre fuerte en España, Felipe Calleja, se posicionó claramente por el bando franquista y precisamente se instaló en San Sebastián para dirigir la delegación comercial. De hecho, por la amplia correspondencia

91 Actas 58 y 63 CTDG 7-10-1938 y 2-12-1938 (AGG064 y AGG069, AGG-GAOJDIT1114-1), esto lo hemos encontrado solo para el caso de Ericsson, no para los pedidos a empresas alemanas.

92 Las vicisitudes de Ericsson en España durante la Guerra Civil se pueden seguir parcialmente en Ericsson, 2015, pp. 27-42.

93 Acta Junta de Accionistas CEE 29-7-1935 (AHEE-AJAC021, CfN-TE E1ca/38). Antes de la GCE el último acta del Consejo de Administración fue el 10-3-1936 (AHEEACA037, CfN-TE E1ca/38) y, en principio, no se reanudó hasta agosto de 1941 (AHEEACA038, CfN-TE E1ca/38), en cambio, durante la GCE sí se celebraron al menos dos juntas de accionistas pero las respectivas actas están desaparecidas en el Archivo de Estocolmo (no hemos podido acceder al archivo de Ericsson en España).

${ }^{94}$ Hay abundancia de documentos en el AGG sobre peticiones de equipos, ofertas y facturas, véase Soler e Iglesia, 2020. Del Archivo Histórico de Ericsson España, correspondencia varia durante 1938 entre LM Ericsson Estocolmo (en adelante LME) y Felipe Calleja (representante comercial en España de Ericsson), (AHEE-VM005, AHEEVM006, AHEE-VM035, signatura original en CfN-TE F7cb-11/Mcr196). 
entre Calleja y los gestores suecos en Estocolmo, sabemos que desde Suecia se tenía conocimiento del suministro de la red de Guipúzcoa al ejército de Franco. Como perteneciente a un país neutral, no podía suministrar directamente al ejército nacional, pero tenemos constancia que sí lo intentó desde sus filiales en Italia y Alemania. En efecto, la matriz sueca hizo consultas a Calleja sobre la idoneidad de este posible suministro directo desde las filiales de Ericsson en Austria e Italia al ejército de Franco, a lo que se le contestó afirmativamente..$^{95}$

También está comprobado que los empresarios suecos, especialmente las grandes corporaciones como Electrolux y otras del sector energético, presionaron al gobierno sueco para que se establecieran relaciones comerciales con el Gobierno de Burgos. ${ }^{96}$ Aunque desde Suecia hubo un cierto apoyo a la causa republicana, este fue gestionado por organizaciones políticas de izquierda y sindicatos de manera ajena al gobierno.

Como prueba de la implicación de Ericsson, algunas personas de los cuerpos técnico y directivo de la matriz sueca visitaron Guipúzcoa en plena guerra. Los motivos fueron dos: para estudiar un ambicioso proyecto de ampliación de la red y la posible externalización de la explotación, de la que se encargaría Ericsson. Volveremos a estos asuntos en el siguiente epígrafe. Realmente tuvo que haber, o bien visitas anteriores de personal sueco a Guipúzcoa o bien de personal español de la CEE a Suecia. ${ }^{97}$

En cuanto a otros suministradores de equipos durante la guerra civil, destacan las empresas alemanas Siemens y Neumeyer, la italiana Pirelli y, entre las españolas, la principal fue Standard Eléctrica (solo la sección de

95 Telegrama de LME a CEE, 5-1-1938 (AHEE-VM022, CfN-TE F7cb-11/Mcr196). Carta de CEE a LME, 7-1-1938, (AHEE-VM023, CfN-TE F7cb-11/Mcr196) (en esta carta además de la consulta concreta, se indica que atendiendo a la amistad del Gobierno Nacional con la Italia Fascista indican que su filial podría ofrecer al Gobierno Militar teléfonos y centrales telefónicas); Carta de LME a CEE, 31-5-1938 sobre informe de venta de material telefónico militar de la filial de Ericsson en Viena (AHEE-VM028, CfN-TE F7cb-11/ Mcr196).

96 Véase Peix Geldart, 2013, pp. 327-331. Aunque Peix no cita el caso de Ericsson, es obvio que por el contenido de nuestras fuentes se deduce que habría que añadirla.

97 En el fondo «Liquidaciones y gastos de la CEE dic-1937 a feb-1938» (AHEEBAL001, CfN-TE E1cb/21), se hace referencia a gastos de salvoconductos entre fronteras y pasaporte del Gobierno Militar, sin concretar el detalle de personas involucradas. Hay otros documentos con similar (desde AHEE-BAL002 hasta AHEE-BAL011, CfN-TE $\mathrm{E} 1 \mathrm{cb} / 21)$. 
cables), aunque también hubo otras menores, como Celaya y Emperanza (fábrica militarizada que luego pasaría a denominarse Acumuladores Tudor), Eguren y Sociedad Anónima de Telefonía. ${ }^{98}$

Evidentemente, la Diputación daba prioridad a las empresas españolas para aquellos productos que no fueran exclusivos de Ericsson, cables y pilas mayoritariamente. Sin duda, el suministro de cables fue el más trascendental para solventar los múltiples destrozos por la contienda. La Diputación no podía contar con su principal proveedor nacional, CEE, cuya fábrica estaba en Getafe bajo control republicano. El proveedor de cables nacional mas importante era Standard Eléctrica, que tenía dos fábricas: en Madrid para equipos de telefonía y en Maliaño (Santander) para cables. La de Madrid estuvo toda la guerra bajo control republicano, igual que la de Maliaño hasta septiembre de 1937, cuando las tropas franquistas se hicieron con el control de toda la provincia cántabra.

Respecto al suministro de empresas alemanas, este formaba parte del abundante apoyo de dichas empresas al estado franquista, tanto directamente al cuerpo de transmisiones del ejército como a redes civiles. Para la RTG se tramitaron varios pedidos a través de la empresa HISMA, que centralizaba todo el comercio entre España y Alemania. ${ }^{99}$

\subsection{El inicio de las negociaciones para la retrocesión de la red al Estado ${ }^{100}$}

Desde 1934 la Diputación tuvo en consideración el problema del fin de la concesión, previsto para 1943, que implicaba la retrocesión al Es-

98 En el AGG hay más de dieciséis referencias con amplia información sobre pedidos a estas empresas de 1936 a 1939; por ejemplo Acta 27 CTDG 22-10-1937 (AGG013, AGG-GAO-JDIT1113-1), para más casos véase Soler e Iglesia, 2020.

99 Hay varios documentos sobre suministros de Siemens, y algunos con la gestión a través de HISMA, por ejemplo «Concursos de suministros 1937 y 1938» (AGG031 y AGG034, AGG-GAO-JDIT1190C-1). Para más casos, Soler e Iglesia, 2020. El proceso de adquisición de material alemán a través de HISMA se analiza en Iglesia y Soler, 2017. Véase también «Informe sobre actividades de HISMA en España, 1940» (AJE004, CDMH-AFNFF-DOC2785).

100 Este asunto ya ha sido tratado exhaustivamente por Gutiérrez Alonso, 1997, e Ibisate, 1998, pero no los aspectos aquí analizados por nosotros, basados en fuentes primarias, en relación con la posibilidad de la externalización por parte de la alemana Siemens y el proyecto de ampliación de Ericsson. 
tado y, por tanto, su absorción por la CTNE. Pero fue en plena guerra civil, en 1937, cuando la CTDG empezó a preparar extensos y rigurosos informes, apoyándose en letrados externos, para justificar la necesidad de prorrogar la concesión. ${ }^{101}$ El punto de partida para esta actuación fue junio de 1937, con la ya citada anulación del Concierto Económico del Estado con las provincias de Guipúzcoa y Vizcaya y, por tanto, el traspaso de los servicios económicos de estas provincias para su gestión por el Estado. Evidentemente, esto afectaba a la posible prórroga de la concesión, de hecho el primer informe sobre este tema se denominó «Supresión del Concierto Económico y su relación con la concesión de la Red Telefónica Provincial»..$^{102}$

La Diputación intentó justificar la necesidad de la prórroga basándose en la excelencia del servicio, considerado de los mejores de Europa, y a las difíciles condiciones al principio de la guerra, lo que implicó un esfuerzo económico y de recursos extraordinarios para restaurar el servicio en bastantes localidades. Se utilizó el dato de la destrucción de la red y el consiguiente esfuerzo inversor posterior como base por la cual era de justicia prolongar la concesión. ${ }^{103}$ Efectivamente, la tenaz oposición de la Diputación a la retrocesión logró que esta se retrasara, principalmente por los argumentos relativos a su apoyo a la sublevación del 18 de julio y a la necesidad de la gestión soberana de la red por las autoridades públicas, y no por una empresa privada, como la CTNE, ya que antes del 18 de julio, «.. esto ha constituido una lamentable dejación por virtud de la cual el Estado ha abandonado derechos esenciales de su soberanía». ${ }^{104}$ Ahora bien, no se consiguió paralizarla, con lo que el Estado volvió a controlar la RTG, y en base al acuerdo con la CTNE, esta la absorbió en 1949.105 Esto provocó una seria amargura en el ingeniero director, lo que le llevó,

101 Todo el expediente del Fondo de la CTDG sobre este tema es muy extenso y abarca desde junio de 1937 hasta abril de 1940, está unificado bajo la misma denominación y signatura, «Expediente Concierto con el Estado», AGG-GAO-JDIT1402-6. En Soler e Iglesia, 2020, se ha dividido en seis partes (AGG101 a AGG106, AGG-GAOJDIT1402-6).

102 Expediente Concierto con el Estado (AGG101, AGG-GAO-JDIT1402-6).

103 Memoria del Servicio Telefónico de noviembre 1939 (AGG096, AGGGAO-JDIT940-A2), también en acta 79 CTDG 9-6-1939 (AGG085, AGG-GAOJDIT940-A2).

104 Ibidem, AGG096, p. 10.

105 Para mayor información puede seguirse: Etxaide Itharte, 1986; Ibisate, 1998; Gutiérrez Alonso, 1997. 
al contrario que el resto del personal, a no querer integrase en la CTNE. Echaide se expresaba así:

«[respecto a] ... los tragos amargos que estamos sufriendo con motivo del traspaso del teléfono a la Compañía Telefónica nacional [...] En cuanto al dolor que estos acontecimientos producen [...] esto lo venía digiriendo desde el final de la guerra civil; y fui viviéndolo todo; la ambición sin escrúpulos de una parte, el pesimismo, la falta de inteligencia, la falta de interés, la ausencia total de patriotismo de la otra. Pude comprobar con qué armas tan desiguales íbamos a luchar. Fuera de $[\ldots]$ algunas honrosas excepciones, de más mérito que peso, he luchado sólo.» ${ }^{106}$

En la fase previa de la negociación, y con el objeto de prorrogar la concesión, la Diputación planteó dos soluciones que estaban relacionadas: un proyecto ambicioso de ampliación de la red para el periodo 1938-1942, con lo que contaba con el apoyo de Ericsson; y además, la posibilidad de subcontratar la explotación de la red a diversas empresas, manteniendo su titularidad la administración guipuzcoana.

En febrero de 1938 Ericsson preparó un proyecto sobre la modernización de la Red Telefónica de Guipúzcoa para el periodo 1938-1942, cuyas partidas principales eran las relativas al aumento de zonas automatizadas (es decir nuevas centrales automáticas), la ampliación de la capacidad de las centrales automáticas existentes y a la modernización de los cables interurbanos. ${ }^{107}$

Respecto a la segunda iniciativa, sobre la subcontratación de la explotación de la red, evidentemente Ericsson era la principal favorita para la adjudicación, por ser el principal proveedor de los equipos. Incluso se planteó que fuera conjunta con la de la Red Municipal de San Sebastián (que recordemos su concesión era ilimitada y de esta forma se forzaría el mantener la concesión de la red provincial). ${ }^{108}$ En realidad, para dicha

106 Carta de Echaide a Constantino Aguinaga, 28-12-1949 (el destacado en negrita es nuestro), disponible en Etxaide Itharte, 1986, p. 58. Hay que señalar que cuando habla de falta de patriotismo, se refiere a patriotismo vasco.

107 Proyecto de Modernización de la Red Telefónica de Guipúzcoa para 1938-1942 (AHEE-AOF001, CfN-TE F5g/50).

108 Informe sobre explotación de la Red 7-1-1937 (ASS011, ASS H-03350-06); Informes Retrocesión de la Red Provincial, 1939 (ASS039 a ASS050, ASS A13.1-3350-3). 
externalización, se establecieron además como candidatas a la CTNE, a Standard Eléctrica o filiales alemanas de ITT (como la Standard alemana) y a Siemens. ${ }^{109}$ La candidatura de Siemens no es una mera opción sin fundamento, ya que en los primeros años de la Segunda Guerra Mundial intentó establecer un monopolio sobre las telecomunicaciones en España, y de hecho aprovechó la Guerra Civil para posicionarse en este sentido. ${ }^{110}$

Por último, una reflexión sobre las palabras de Echaide quejándose de que no se hizo todo lo posible desde las autoridades guipuzcoanas. En nuestra opinión, y al margen del esfuerzo que hubiera podido hacerse desde la Diputación, una vez ya la mayoría de las acciones de la CTNE en manos del Estado y controlada la dirección de la empresa por personal español, depurado y por tanto adicto a la dictadura, ${ }^{111}$ el nuevo régimen no iba a desistir en su empeño de completar el monopolio de la CTNE, con una red tan importante como la guipuzcoana, por lo que no habría facilitado - más bien al contrario - la renovación de la concesión de la red provincial, con lo que esta posibilidad era prácticamente nula.

\section{Conclusiones}

Al comienzo de la Guerra Civil, el servicio telefónico en la Península estaba gestionado por la CTNE, salvo en el caso de las redes telefónicas de Guipúzcoa y San Sebastián, que se mantendrían como concesiones independientes hasta después de terminado el conflicto. Esta circunstancia, el hecho de haberse conservado sus archivos, y que éstos sean accesibles, ha permitido la realización de este estudio de la Red Provincial (queda pendiente el de la Red Urbana). Lamentablemente esto no se cumple para el caso del resto de la red telefónica controlada por una CTNE dividida en dos durante la guerra, y cuyos archivos documentales no son accesibles en el momento actual, quedando este periodo pendiente de una investigación sistemática.

109 Expediente Concierto con el Estado 1937-1938 (agg102, AGG-GAO-JDIT1402-6) y Acta 10 DN, 30-12-1937 (AGG-DN010, AGG-GAO-JDTL0388).

110 Véase Iglesia y Soler, 2017 y «De cómo la CTNE pudo pertenecer a la Siemens de la Alemania Nazi: muchas incógnitas todavía» (https://historiatelefonia.com/2015/05/03/).

111 Informe sobre la adquisición de Telefónica 24-11-1942 (AJE011, CDMH-AFNFFDOC27186). 
Se constata en los documentos estudiados el ejercicio del control militar, con la censura de las comunicaciones y la depuración del personal empleado en la red, tanto en un bando como en el otro. Este control fue fundamental para la necesaria coordinación entre las autoridades civiles y militares en la retaguardia.

El esfuerzo bélico restó capacidad a la gestión de la red, requiriéndose la entrega de material telefónico para los cuerpos de transmisiones del ejército nacional, y con un problema grave de escasez de personal. Pero, a su vez, es indudable que dicho suministro fue de suma importancia para el ejército de Franco.

En definitiva, se confirma con este estudio nuestra hipótesis inicial, a saber, que no se puede tener una visión completa de la historia contemporánea del sector industrial asociado a las telecomunicaciones, sin el periodo de la GCE, la II Guerra Mundial y sus consecuencias. Lo mismo ocurre en cuanto al propio análisis de la GCE, en su aspecto tanto civil como militar. El caso visto de la Red Telefónica de Guipúzcoa lo permite parcialmente, pero se hace necesario completarlo con el estudio del resto de la red telefónica a nivel nacional controlada por la CTNE, en temas como el del control militar en ambas zonas, la depuración del personal, la gestión de los destrozos en la red y su solución.

Lo aquí analizado respecto a la RTG es solo una aproximación, habiendo aspectos que requieren mayor profundización, como las características específicas en la gestión de la red por la situación de la guerra y el entorno de crisis internacional. De esta forma hemos querido mostrar aquí una visión general de estos temas, lo que permitirá en el futuro profundizar en ellos, gracias a la disponibilidad de las fuentes utilizadas. Ahora bien, a la hora de estos posibles estudios, sería conveniente hacerlos desde una perspectiva comparada con el caso de la CTNE. Un ejemplo claro es el de los respectivos procesos de depuración. ${ }^{12}$

Un aspecto fundamental para otros estudios es el papel jugado por las empresas suministradoras de equipos, lo que permitirá analizar tanto las interacciones internacionales en la Guerra Civil, por ejemplo el comercio exterior desde otra perspectiva escasamente investigada, como los intereses estratégicos a nivel nacional relacionados con el sector de las telecomunicaciones y que fueron también determinantes en la marcha de la

112 Por ejemplo, ya ha sido analizado el caso de la depuración en el personal de Correos (Bordes, 2009), lo que puede ayudar a dicha perspectiva comparada en procesos de depuración, y por tanto con más motivo es necesario realizar lo propio con la CTNE. 
guerra y en la evolución económica en la retaguardia en todo el país. Ciertamente, para este análisis, no es suficiente con el caso aquí propuesto, se hace necesario extenderlo a todo el territorio español y, por tanto, a la CTNE.

\section{Bibliografía}

AIZPURU, Gregorio, Guipúzcoa. Sesenta años del teléfono automático, Diputación Foral de Guipúzcoa, Zarautz, 1986.

ALÍA MIRANDA, Francisco, Julio de 1936, Conspiración y alzamiento contra la Segunda República, Crítica, Barcelona, 2011.

APRAIZ, Amaya, MARTÍNEZ, Ainara y HERRERAS, Beatriz, «Gipuzkoa militarizada. Empresarios y obreros Guipuzcoanos ante el nuevo orden militar, 1937-1939», en ÁLVAREZ ARECES, Miguel Ángel (coord.): El Patrimonio Industrial en el contexto histórico del franquismo 1939-1975, TICCIHEspaña, Madrid, 2016, pp. 373-380.

BAHAMONDE MAGRO, Angel y OTERO CARVAJAL, Luis Enrique, «El teléfono. El nacimiento de un nuevo medio de comunicación, 1877-1936», en BAHAMONDE MAGRO, Ángel, MARTÍNEZ LORENTE, Gaspar y OTERO CARVAJAL, Luis Enrique: Las comunicaciones en la construcción del Estado contemporáneo en España. 1700-1936, Madrid, Ministerio de Obras Públicas, Transportes y Medio Ambiente, 1993.

BARCIELA LÓPEZ, Carlos y LÓPEZ ORTIZ, M. ${ }^{\mathrm{a}}$ Inmaculada, «Una nación en crisis y dos economías enfrentadas. La historiografía económica de la Guerra Civil Española»Studia Historica, Historia Contemporánea, 2014, pp. 197-224.

BARCIELA LÓPEZ, Carlos y LÓPEZ ORTIZ, M. ${ }^{a}$ Inmaculada, «En defensa de la historia. Mitos, represión y otras cuestiones económicas en el debate historiográfico de la Guerra Civil», en Ángel VIÑAS y Juan Andrés BLANCO (dirs.), La Guerra Civil española, una visión bibliográfica, Marcial Pons Historia, 2017, pp. 246-283.

BARRUSO, Pedro, Verano y revolución. La Guerra Civil en Gipuzkoa, Luis Haranburu Editor, San Sebastián, 1996 (disponible parcialmente en http:// www.gipuzkoa1936.com/verano-e.php).

BARRUSO, Pedro, Violencia política y represión en Guipúzcoa durante la Guerra Civil y el primer franquismo (1936-1945), Hiria editor, San Sebastián, 2005.

BORDES MUÑOZ, Juan Carlos, El servicio de Correos durante el régimen franquista (1936-1975) Depuración de funcionarios y reorganización de los servicios postales, Colección Biblioteca de Historia Social, Ediciones Cinca, Madrid, 2009. 
BORREGUERO, Cristina (coord.), Historia de las tecnologías de la información y las comunicaciones al servicio de la defensa, Universidad de Burgos, Burgos, 2017.

BUCES CABELLO, Javier y QUEREJETA CASARES, Elisa, Personal de la Diputación de Gipuzkoa, 1936, Diputación Foral de Gipuzkoa, San Sebastián, 2016.

CALVO CALVO, Ángel, «El teléfono en España antes de Telefónica (18771924)», Revista de Historia Industrial, 13, 1998, pp. 59-81. (https://www. raco.cat/index.php/HistoriaIndustrial/article/view/63292/84930).

CALVO CALVO, Ángel, Historia de Telefónica: 1924-1975. Primeras décadas: tecnología, economía y política, Ariel, Fundación Telefónica, Madrid, 2010. (https://www.fundaciontelefonica.com/cultura-digital/publicaciones/78/).

CALVO CALVO, Ángel, Telecomunicaciones y el nuevo mundo digital en España: la aportación de Standard Eléctrica, Ariel, Fundación Telefónica, Madrid, 2014. (https://www fundaciontelefonica.com/cultura-digital/ publicaciones/266/).

DE SALAS, Juan, «Vicisitudes del Teléfono en la Guerra de España», Anales de Mecánica y Electricidad, 28, pp. 249-253, 311-319, 366-380, 1941.

DIPUTACIÓN DE GUIPÚZCOA, Reglamento de la Red Telefónica Provincial de Guipúzcoa, San Sebastián, 1911 (http://w390w.gipuzkoa.net/WAS/ CORP/DBKVisorBibliotecaWEB/visor .do? ver\&amicus=98039).

ECHAIDE LIZASOÁIN, Ignacio María, Red Telefónica de Guipúzcoa: Descripción histórica y estadística, Publicaciones de la Red Telefónica de Guipúzcoa, San Sebastián, 1923 (http://w390w.gipuzkoa.net/WAS/CORP/ DBKVisorBibliotecaWEB/visor.do?ver\&amicus=170713).

ECHAIDE LIZASOÁIN, Ignacio María, Red Telefónica de la Diputación de Guipúzcoa. Resumen descriptivo, histórico y estadístico, Publicaciones de la Red Telefónica de Guipúzcoa, San Sebastián, 1929 (http:// w390w.gipuzkoa.net/WAS/CORP/DBKVisorBibliotecaWEB/visor. do?ver\&amicus=50017).

ECHAIDE LIZASOÁIN, Ignacio María, Memoria relativa al ejercicio de 1934. Red Telefónica de Guipúzcoa, Publicaciones de la Red Telefónica de Guipúzcoa, San Sebastián, 1935.

ECHAIDE LIZASOÁIN, Ignacio María, Los veinte primeros años de la red telefónica de Guipúzcoa (1908-1928), Diputación de Guipúzcoa, San Sebastián, 1954.

ERICSSON, «The New Ericsson Automatic Exchanges in San Sebastian and Vecinity», Ericsson Review Vol. 3, pp. 50-53, 93-100, 1926 (https:// www.ericsson.com/assets/local/about-ericsson/ericsson-history/lme-review/ documents/da2011-35504-ericsson_review_vol_3_1926.pdf). 
ERICSSON, Ericsson en España. Una historia de éxito, valores y personas, Ericsson-Planeta, Madrid, 2015 (http://www .asociacionpensionistasericsson. es/Ericsson-en-Espana.pdf).

ETXAIDE ITHARTE, Yon, Etxaide Jauna (Inazio Maria Etxaide Lizasoain injinadorearen bizitza, inguru-giroa eta lanak), Erein, San Sebastián, 1986.

FUENTES QUINTANA, Enrique. y COMÍN, Francisco (eds.), Economía y Economistas Españoles en la Guerra Civil, Galaxia Gutemberg, Barcelona, 2008.

FUSI AIZPURUA, Juan Pablo, «La Guerra Civil en el País Vasco: una perspectiva general». En GARITAONDÍA y GRANJA (eds.): La Guerra Civil en el País Vasco 50 años después, Universidad del País Vasco, Bilbao, 1987, pp. 43-50.

GONZÁLEZ PORTILLA, Manuel, «La economía de guerra en el País Vasco al servicio del ejército de Franco». En GARITAONDÍA y GRANJA (eds.): La Guerra Civil en el País Vasco 50 años después, Bilbao: Servicio Editorial Universidad del País Vasco, 1987, pp. 277-286.

GUTIÉRREZ ALONSO, Jaime, Integración de las redes telefónicas en la CTNE, Tesis Doctoral, Universidad del País Vasco, 1997 (https://historiatelefonia. com/2014/02/17/).

GUTIÉRREZ AROSA, Jesús, La Guerra Civil en Eibar y Elgeta, Eibarko Udala, Eibar, 2007 (disponible parcialmente en https://egoibarra.eus/es/ publicaciones/libros-de-eibar/la-guerra-civil-en-eibar-y-elgeta).

IBISATE ELICEGUI, María Luisa, La telefonía en Guipuzkoa: un modelo original, Fundación Kutxa, San Sebastián, 1998.

IGLESIA MEDINA, José Ramón y SOLER FERRÁN, Pablo, «Suministro de equipos de telecomunicaciones para el ejército del general Franco durante la Guerra Civil». En BORREGUERO (coord.): Historia de las tecnologías de la información y las comunicaciones al servicio de la defensa, Universidad de Burgos, Burgos, 2017, pp. 275-290 (https://historiatelefonia.files. wordpress.com/2019/12/iglesia-soler2017.pdf).

MARTÍNEZ RUIZ, Elena, Guerra Civil, comercio y capital extranjero. El sector exterior de la economía española (1936-1939), Ediciones Banco de España, Madrid, 2006 (https://dialnet.unirioja.es/servlet/ articulo? codigo $=2236618$ ).

NIETO I TRULLÀS, Josep, Politiques de telecomunicació a Espanya: els origens, l'estructuració $i$ el desenvolupament del sistem telefònic (1877-1936). Tesis Doctoral, Deparment de Periodisme, Universitat Autónoma de Barcelona, Barcelona, 1995.

OTERO CARVAJAL, Luis Enrique, «Las telecomunicaciones en la España contemporánea, 1855-2000», Cuadernos de Historia Contemporánea, 29, 
2007, pp. 119-152 (http://revistas.ucm.es/index.php/CHCO/article/view/ CHCO0707110119A/6782).

PEIX GELDART, Benito, Relaciones políticas y diplomáticas entre España y Suecia de 1931 a 1939, Tesis doctoral, Universidad de Valladolid, Valladolid, 2013 (https://uvadoc.uva.es/bitstream/10324/3609/1/TESIS372-130930. pdf).

PÉREZ YUSTE, Antonio, La Compañía Telefónica Nacional de España en la dictadura de Primo de Rivera (1923-1930), Tesis Doctoral, Universidad Politécnica de Madrid, 2004 (http://oa.upm.es/472/1/ANTONIO_PEREZ_ YUSTE.pdf).

ROMERO FRÍAS, Rafael, Colección Histórico-Tecnológica de Telefónica, Fundación Arte y Tecnología, Telefónica, Madrid, 1994 (http://forohistorico. coit.es/index.php/biblioteca/libros-electronicos/item/libro-coleccionhistorico-tecnologica-de-telefonica).

SÁNCHEZ ASIAÍN, José Ángel, La financiación de la guerra civil española, Crítica, Barcelona, 2012.

SOLER FERRÁN, Pablo e IGLESIA MEDINA, José Ramón, Fondos Documentales sobre Telecomunicaciones en la Guerra Civil Española, 2020. En edición, prevista su publicación digital en 2020 por el COIT-FHT (Colegio Oficial de Ingenieros de Telecomunicación-Foro Histórico de las Telecomunicaciones), ISBN en trámite. (Disponible versión provisional en https://historiatelefonia.files.wordpress.com/2020/01/catv5dic2019.pdf).

VIÑAS, Ángel y BLANCO, Juan Andrés Blanco (dirs), La Guerra Civil española, una visión bibliográfica, Marcial Pons Historia, Madrid, 2017.

THOMAS, Hugh, La Guerra Civil Española, 1926-1939, Grijalbo, Barcelona, 1976.

Nota: fecha de consulta de todas las url, febrero 2019.

\section{Apéndice 1. Fuentes consultadas}

\section{Fuentes orales}

Información proporcionada por: Ana María Echaide, hija de Ignacio María Echaide, mediante entrevista presencial el 20-10-2016 y correos electrónicos; la familia Mitxelena Rekalde (nietos de Jenaro Mitxelena) mediante entrevista telefónica y correos electrónicos. 
Fuentes de archivos $^{113}$

Archivo General de Guipúzcoa (AGG-GAO): Fondo Comisión de Teléfonos de la Diputación de Guipúzcoa (AGG, AGG-GAO) (las Actas de la Comisión de Teléfonos vienen indicadas con el acrónimo Acta CTDG); Fondo Diputación de Guipúzcoa en San Sebastián (zona nacional) (AGG-DN, AGGGAO); Fondo Diputación de Guipúzcoa en Motrico y Bilbao (zona republicana) (AGG-DR, AGG-GAO).

Centrum för Näringslivshistoria (Centre for Business History) en Estocolmo (Archivo Telefonaktiebolaget LM Ericsson) (CfN-TE): Fondo LTM Ericsson Olof Hult (AHEE-AOF, CfN-TE), Balances (AHEE-BAL, CfN-TE) y Ventas (AHEE-VM, CfN-TE); Fondo Compañía Española Ericsson, Actas de Consejo de Administración (AHEE-ACA, CfN-TE) y Actas de Junta de Accionistas (AHEE-AJAC, CfN-TE).

Archivo del Ayuntamiento de Donostia-San Sebastián (ASS), fondo de la Red Telefónica Urbana (ASS, ASS).

Archivo Histórico Nacional (AHN), Fondos Contemporáneos (AHN, AHN-FC), Causa General de la Guerra Civil en Guipúzcoa (AHN-FC-CAUSA-GENERAL).

Archivo Histórico de la CNT, Fundación Anselmo Lorenzo (ACNT).

Centro Documental de la Memoria Histórica (CDMH): Fondos propios del CDMH (CDMH, CDMH-PS) y Fondo de la Fundación Nacional Francisco Franco (AJE ${ }^{114}, \mathrm{CDMH}-\mathrm{FNFF}$ ).

Archivo Histórico de la Oficina Española de Patentes y Marcas (AHOEPM, AHOEPM).

\section{Otras fuentes}

Blog https://historiatelefonia.com.

Boletín Oficial del Estado (BOE), Gazeta: colección histórica.

Diario Oficial del País Vasco (DOPV) (1936-1937).

${ }^{113}$ El sistema de citación de las fuentes se realiza con una doble signatura, primero la establecida en nuestra catalogación de documentos sobre telecomunicaciones en la GCE (Soler e Iglesia, 2020) y después la del archivo original. Por ejemplo la siguiente cita: (AGG012, AGG-GAO-JDIT1113-1), se refiere al mismo documento, AGG012 según nuestra catalogación y AGG-GAO-JDIT1113-1 según la signatura del expediente original. Desde la catalogación citada se puede acceder mediante hiperenlaces a la mayoría de los documentos digitalizados, gracias a convenios con los respectivos archivos.

114 En nuestra catalogación lo hemos denominado Archivo Jefatura del Estado. 
Libro de Actas del Cabildo de Tenerife.

Diario La Voz de España (San Sebastián, 1937).

\section{Apéndice 2. Acrónimos ${ }^{115}$}

CAMPSA: Compañía Arrendataria del Monopolio del Petróleo Sociedad Anónima.

CEE: Compañía Española Ericsson.

CTDG: Comisión de Teléfonos de la Diputación de Guipúzcoa.

CNT: Confederación Nacional del Trabajo.

CTNE: Compañía Telefónica Nacional de España.

GCE: Guerra Civil Española.

HISMA: Sociedad Hispano Marroquí de Transportes.

ITT: International Telephone \& Telegraph.

LME: L. M. Ericsson.

PNV: Partido Nacionalista Vasco.

RTG: Red Telefónica de Guipúzcoa.

\section{Datos de los autores}

Pablo Soler Ferrán (ferranpablo@gmail.com) es licenciado en Ciencias Físicas y doctor en Filosofía por la Universidad Complutense de Madrid, versando su tesis doctoral sobre la Teoría de la Relatividad en España. Es miembro del Foro Histórico de las Telecomunicaciones (Madrid) y administrador del blog https:/ historiatelefonia.com. Sus principales líneas de investigación son: Historia de la Física en España, Historia de las Telecomunicaciones y Patrimonio Histórico-Tecnológico asociado. Es autor del libro El inicio de la ciencia nuclear en España (Sociedad Nuclear Española, Madrid, 2017). Actualmente es alumno del Máster de Historia Contemporánea por la Universidad Complutense de Madrid.

José Ramón Iglesia Medina (jramoniglesia@gmail.com; https://orcid. org/0000-0001-6950-1354) es Ingeniero de Telecomunicaciones por la Universidad Politécnica de Madrid. Ha desarrollado su carrera profesional durante más de treinta años en el sector de las telecomunicaciones. Sus intereses investigadores se centran en Historia de las Telecomunicaciones y Patrimonio Histórico-Tecnológico asociado, siendo actualmente responsable de la Senda Museo en el Foro Histórico de las Telecomunicaciones. Es también administrador del blog https:/ historiatelefonia.com. Fuentes.

115 Los acrónimos referentes a los fondos documentales aparecen en el apéndice 1 